\title{
Dust ice nuclei effects on cirrus clouds
}

\author{
M. Kuebbeler ${ }^{1}$, U. Lohmann ${ }^{1}$, J. Hendricks ${ }^{2}$, and B. Kärcher ${ }^{2}$ \\ ${ }^{1}$ Institute for Atmospheric and Climate Science, ETH Zurich, Switzerland \\ ${ }^{2}$ Deutsches Zentrum für Luft- und Raumfahrt (DLR), Institut für Physik der Atmosphäre, Oberpfaffenhofen, Germany
}

Correspondence to: U. Lohmann (ulrike.lohmann@env.ethz.ch)

Received: 16 March 2013 - Published in Atmos. Chem. Phys. Discuss.: 12 April 2013

Revised: 6 February 2014 - Accepted: 10 February 2014 - Published: 26 March 2014

\begin{abstract}
In order to study aerosol-cloud interactions in cirrus clouds, we apply a new multiple-mode ice microphysical scheme to the general circulation model ECHAM5HAM. The multiple-mode ice microphysical scheme allows for analysis of the competition between homogeneous freezing of solution droplets, deposition nucleation of pure dust particles, and immersion freezing of coated dust particles and pre-existing ice. We base the freezing efficiencies of coated and pure dust particles on the most recent laboratory data. The effect of pre-existing ice, which has been neglected in previous ice nucleation parameterizations, is to deplete water vapour by depositional growth and thus prevent homogeneous and heterogeneous freezing from occurring. As a first step, we extensively tested the model and validated the results against in situ measurements from various aircraft campaigns. The results compare well with observations; properties such as ice crystal size and number concentration as well as supersaturation are predicted within the observational spread.

We find that heterogeneous nucleation on mineral dust particles and the consideration of pre-existing ice in the nucleation process may lead to significant effects: globally, ice crystal number and mass are reduced by 10 and $5 \%$, whereas the ice crystals' size is increased by $3 \%$. The reductions in ice crystal number are most pronounced in the tropics and mid-latitudes in the Northern Hemisphere. While changes in the microphysical and radiative properties of cirrus clouds in the tropics are mostly driven by considering pre-existing ice, changes in the northern hemispheric midlatitudes mainly result from heterogeneous nucleation. The so-called negative Twomey effect in cirrus clouds is represented in ECHAM5-HAM. The net change in the radiation budget is $-0.94 \mathrm{~W} \mathrm{~m}^{-2}$, implying that both heterogeneous nucleation on dust and pre-existing ice have the potential to
\end{abstract}

modulate cirrus properties in climate simulations and thus should be considered in future studies.

\section{Introduction}

Cirrus clouds cover approximately $30 \%$ of the Earth's surface and play an important role in modulating the climate system (Wylie and Menzel, 1999). As with all other clouds, they scatter solar radiation back into space (the albedo effect) and absorb and re-emit terrestrial radiation (the greenhouse effect). Contrary to other clouds, cirrus clouds exert a positive net cloud forcing to the Earth-atmosphere system (Chen et al., 2000). This, however, applies only for moderate to thin cirrus clouds and it is assumed that thick cirrus clouds exert a negative net cloud forcing (Chen et al., 2000). Fusina et al. (2007) showed that the transition of positive to negative net cloud forcing for mid-latitudinal cirrus depends on the ice crystal number concentration and thus on the cooling rate and formation mechanism (Haag and Kärcher, 2004; Spichtinger and Gierens, 2009).

Cirrus clouds can form via two different ice nucleation mechanisms: homogeneous freezing of supercooled solution droplets (Koop et al., 2000) and heterogeneous nucleation of solid or crystalline aerosol particles, which are termed ice nuclei (IN) (Vali, 1985). Whereas homogeneous freezing requires high supersaturations $\left(\mathrm{RH}_{\mathrm{i}} \sim 150-170 \%\right)$ the surface of an IN lowers the energy barrier for ice nucleation in the case of heterogeneous nucleation, and ice crystals can form at lower supersaturations and/or at warmer temperatures as compared to homogeneous freezing (Pruppacher and Klett, 1998). The knowledge about heterogeneous nucleation in the upper troposphere is poor, and direct measurements in cirrus clouds remain challenging (Cziczo et al., 
2013; DeMott et al., 2011; Cantrell and Heymsfield, 2005). DeMott et al. (2003) measured the IN composition of midlatitudinal free-tropospheric air and found that mineral dust, fly ash and metallic particles are the most abundant IN. Several laboratory-based studies have consistently shown that mineral dust might act as good IN at $T<238 \mathrm{~K}$ (Zuberi et al., 2002; Archuleta et al., 2005; Möhler et al., 2006; Field et al., 2006b; Welti et al., 2009; Koehler et al., 2010). However, the ice nucleation ability of mineral dust is most likely dampened when the dust aerosol becomes coated with soluble material, such as organics and sulfuric acid (Möhler et al., 2008; Koehler et al., 2010; Cziczo et al., 2009) (see also the review paper about heterogeneous ice nucleation by Hoose and Möhler, 2012).

Several years ago, field observations reported persistently high supersaturations inside and outside of cirrus clouds in the tropical tropopause layer (TTL), and with that the traditional understanding of cirrus cloud formation was called into question (Jensen et al., 2005; Peter et al., 2006). This was called the "supersaturation puzzle" and since then much research into the matter has been done. Krämer et al. (2009) found that high supersaturations can be explained with observed ice crystal number concentrations which are unexpectedly low and turned the "supersaturation" into a "nucleation puzzle". A possible explanation for low ice crystal number concentrations (ICNC) is the suppression of homogeneous freezing through heterogeneous ice nucleation. Kärcher and Lohmann (2003) showed that even low IN concentration can prevent homogeneous freezing from occurring and thus drastically affect the number of ice crystals formed in a nucleation event. Recently, Spichtinger and Krämer (2012) showed that low ICNC and thus high supersaturations can be explained by homogeneous nucleation and consecutive heterogeneous and homogeneous nucleation when the complex dynamics in the TTL, namely slow large-scale ascent combined with high-frequency short waves, are taken into account.

The role of homogeneous vs. heterogeneous nucleation in cirrus clouds and the possible impact of heterogeneous IN on cirrus clouds has also been studied in general circulation models (GCM). First attempts were made by Lohmann et al. (2008), who used a rather simplified description of the competition of homogeneous and heterogeneous nucleation. Heterogeneous nucleation is assumed to take place in a particular grid box if the number concentration of heterogeneous IN exceeds a certain threshold and homogeneous freezing takes place elsewhere. They found larger ice crystals, enhanced precipitation and reduced ice mass inducing changes in the radiation budget when mineral dust and black carbon were assumed to act as IN. Recently, more sophisticated parameterizations treating the competition of homogeneous and heterogeneous nucleation have been developed (Kärcher et al., 2006; Liu and Penner, 2005; Barahona and Nenes, 2009). The advantage of the parameterization of Kärcher et al. (2006) over the other two is that it not only accounts for the competition between homogeneous and heterogeneous nucleation but also takes the depositional growth of pre-existing ice crystals into account. The presence of ice crystals prior to a nucleation event can prevent homogeneous and heterogeneous nucleation from occurring due to the depletion of water vapour by depositional growth. Hendricks et al. (2011) incorporated this parameterization into the ECHAM4 GCM and found important effects on the overall cirrus properties, with decreases in the mean ICNC by up to $20 \%$.

In this study we show results of the parameterization of Kärcher et al. (2006) incorporated into ECHAM5-HAM. We use a different aerosol scheme than Hendricks et al. (2011) and treat sub-grid-scale vertical velocity differently. Hendricks et al. (2011) concluded that the vertical velocity is a key parameter driving the microphysics in cirrus clouds and thus needs to be better constrained. In addition to the turbulent-kinetic-energy-based scheme estimating the unresolved fluctuations in the vertical velocity (Lohmann and Kärcher, 2002; Lohmann et al., 2004), we account for orographic cirrus clouds which form in the lee of mountains (Joos et al., 2008).

We analyse the functionality of the new cirrus scheme implemented in ECHAM5-HAM by considering the following aspects: firstly, we analyse the role of homogeneous vs. heterogeneous nucleation and the climatic effects of heterogeneous IN and pre-existing ice on simulated cirrus clouds, and secondly, we compare the results of the new cirrus scheme with observations from in situ measurements.

\section{Model description}

\subsection{ECHAM5-HAM}

ECHAM5 is a general circulation model (Roeckner et al., 2003) developed at the Max Planck Institute for Meteorology in Hamburg. ECHAM5-HAM includes a two-moment microphysical cloud scheme as well as a two-moment aerosol module. The Hamburg Aerosol Module (HAM) (Stier et al., 2005; Zhang et al., 2012) predicts the mixing state as well as aerosol number concentration and mass mixing ratio of seven aerosol modes. These seven modes are separated into four internally mixed aerosol modes and three externally mixed aerosol modes. HAM includes the major aerosol species sulfate (SU), black carbon (BC), particulate organic matter (POM), sea salt (SS) and mineral dust (DU). The size distribution is given by a superposition of the log-normal modes.

Dust emissions are described following Tegen et al. (2002) and thus depend on wind and hydrological conditions of the surface. Freshly emitted dust is assumed to be insoluble and of the size of $0.05<r<1 \mu \mathrm{m}$. The ageing of aerosols in the atmosphere through coagulation or condensation of water vapour and sulfuric acid is described in HAM by shifting aerosols from the externally mixed to the internally mixed 
modes. The sulfur cycle is based on Feichter et al. (1996) and treats dimethyl sulfide (DMS), sulfur dioxide $\left(\mathrm{SO}_{2}\right)$ and sulfate $\left(\mathrm{SO}_{4}^{2-}\right)$ prognostically. The chemical reactants necessary for the sulfur cycle are prescribed as monthly mean fields.

The stratiform cloud scheme is coupled to HAM and treats mass and number of cloud water and ice prognostically. ECHAM5-HAM distinguishes between mixed-phase and cirrus clouds based on temperature $(238 \mathrm{~K}<T<273 \mathrm{~K}$ : mixed-phase clouds; $T<238 \mathrm{~K}$ : cirrus clouds) and uses different parameterizations for both cloud types. Dust and black carbon can initiate ice formation in mixed-phase clouds at water saturation of $238 \mathrm{~K}<T<273 \mathrm{~K}$; externally mixed dust particles can initiate contact nucleation in the presence of supercooled water droplets following the parameterization of Levkov et al. (1992), as described in Lohmann and Diehl (2006). The temperature dependence of the number of contact nuclei is based on wind tunnel experiments described in Diehl et al. (2006). Internally mixed dust and black carbon particles can initiate immersion freezing in supercooled cloud droplets, which is parameterized according to the stochastic freezing hypothesis as described in Diehl and Wurzler (2004). Again, the temperature dependence of the number of contact nuclei is based on wind tunnel experiments (Lohmann and Diehl, 2006).

In cirrus clouds, homogeneous freezing of solution droplets below water saturation and heterogeneous nucleation of dust can take place. We introduce the physically based parameterization of Kärcher et al. (2006) into ECHAM5-HAM in order to treat ice nucleation and depositional growth in cirrus clouds in a competitive manner. This new cirrus scheme is described in Sect. 2.2. In order to allow for supersaturation with respect to ice required for cirrus cloud formation, we abandon the saturation adjustment scheme. Instead, the depositional growth equation is solved (Lohmann et al., 2004).

The diagnostic cloud cover scheme by Sundqvist et al. (1989) is used. It is based on the grid-mean relative humidity and assumes that a grid box is partly covered by clouds when a critical relative humidity is exceeded and is totally covered when saturation is reached. Since we allow for supersaturations with respect to ice in order to parameterize homogeneous and heterogeneous nucleation, the Sundqvist scheme leads to a cloud cover $b_{\mathrm{c}}=1$ (as soon as ice crystals nucleate and growth occurs) or $1>b_{\mathrm{c}} \geq 0$ (in ice-subsaturated air). This means that a freshly nucleated cirrus cloud covers the whole grid box and fractional cirrus cloud cover is only possible if the air is subsaturated with respect to ice and the cirrus cloud is in its dissolving stage of sublimation. Fractional cloud cover for freshly nucleated cirrus clouds thus cannot be diagnosed as a drawback of the introduction of supersaturation in this scheme. As discussed in Kärcher and Burkhardt (2008), treating fractional cirrus cloud cover prognostically will ensure a physical consistency between fractional cirrus cloud coverage and ice microphysics and should be aimed for in future studies.

Current GCMs are not able to resolve small-scale variability of the vertical velocity; however, it has been shown that it is important to consider this in the context of ice nucleation (Kärcher and Lohmann, 2002). Sub-grid variability of the vertical velocity was introduced into ECHAM by adding a turbulent component, $w_{\mathrm{t}}$, based on the turbulent kinetic energy to the grid box mean value, $w_{1}$ (Kärcher and Lohmann, 2002):

$w=w_{1}+w_{\mathrm{t}}=w_{1}+0.7 \sqrt{\mathrm{TKE}}$,

where TKE is the turbulent kinetic energy. In order to account for orographically induced cirrus clouds, which form in the lee of mountains, the formulation of the vertical velocity has been extended. We assume that, following Joos et al. (2008), the turbulent component is dominated by the vertical velocity of a gravity wave $w_{\mathrm{gw}}$ in the case of orography:

$w=w_{1}+w_{\mathrm{gw}}=w_{1}+k \cdot U \cdot \min \left(\delta h, \delta h_{\mathrm{sat}}\right)$

with $k$ wave number, $U$ horizontal wind speed, $\delta h$ amplitude of a gravity wave, and $\delta h_{\text {sat }}$ saturation amplitude of a gravity wave. The treatment of sub-grid-scale variability in vertical winds in cirrus conditions remains, however, an elusive research issue (Kärcher, 2012), as in situ measurements hint at a significant mesoscale forcing of temperature fluctuations, unresolved in global models (Hoyle et al., 2005).

Additional cloud processes that are considered in ECHAM5 are as follows: phase transitions between water compounds other than freezing (condensation, evaporation, deposition, sublimation, melting), precipitation processes (aggregation, accretion, autoconversion), melting/sublimation of snow and evaporation of rain (Lohmann et al., 2008).

\subsection{New cirrus scheme}

In order to simulate aerosol-cloud interactions in cirrus clouds, a new physically based parameterization (Kärcher et al., 2006) has been implemented into ECHAM5-HAM. The new scheme applies a multiple ice mode approach and considers the following four different ice modes competing for the available water vapour during nucleation and depositional growth:

- homogeneous freezing of supercooled solution droplets (HOM),

- deposition nucleation on externally mixed dust (DU),

- freezing of supercooled solution droplets induced by dust immersions (DU-COATED),

- pre-existing ice crystals (PREEX).

We distinguish between immersion freezing of internally mixed dust and deposition nucleation of externally mixed 
dust because several studies have shown that the ice nucleation ability is different for pure and coated dust particles (Möhler et al., 2008). A detailed description on the ice nucleation properties of externally and internally mixed aerosols is given in Sect. 2.2.1.

The pre-existing ice mode represents all ice crystals which are already in a grid box before ECHAM calculates cirrus ice nucleation. This comprises ice crystals from previous time steps as well as ice crystals transported into cirrus clouds but originating from other sources such as detrainment from deep convective clouds or ice crystals formed in mixed-phase clouds.

The competition between the four different ice modes is realized by a subsequent freezing of aerosol types (starting with the most efficient IN and ending with homogeneous freezing) and the concept of a reduced vertical updraught $w_{\text {ice }}$ caused by the consumption of water vapour by depositional growth of pre-existing ice.

In the case of supersaturation, and if there are ice crystals present, the cirrus scheme condenses mass on these preexisting ice crystals and removes that from the actual supersaturation. However, only as much supersaturation as needed is depleted for this depositional growth during one time step. If the supersaturation is high enough to activate ice nuclei or even exceeds that needed for homogeneous freezing, then the different freezing modes and the pre-existing ice compete for the available supersaturation. This competition for supersaturation is the new aspect of cirrus formation introduced in this study (for more details please refer to Kärcher et al., 2006). The new cirrus scheme requires that saturation adjustment for cirrus clouds is abandoned. This was introduced in a previous version of ECHAM when homogeneous freezing of supercooled solution aerosol for cirrus cloud formation was implemented (Lohmann and Kärcher, 2002). This version was extended to account for pure heterogeneous freezing in grid boxes in which the dust aerosol concentrations were sufficiently high and validated in Lohmann et al. (2008).

Due to their low number concentrations, ice crystals formed via heterogeneous nucleation can grow to larger sizes than homogeneously formed ice crystals. In order to avoid instabilities in the model induced by too fast sedimentation of these large ice crystals, we transfer ice crystals with $R_{\mathrm{i}}>100 \mu \mathrm{m}$ to snow crystals, which are assumed to precipitate, melt or sublimate below cloud base within one time step. This separation between ice crystals and snow follows Levkov et al. (1992).

We introduce the new scheme into ECHAM5-HAM in a similar way as it was done by Hendricks et al. (2011) in ECHAM4. However, we only apply the multiple ice mode concept to nucleation and depositional growth. All other processes such as aggregation, accretion and ice transport are treated in an unimodal way using the unimodal ice crystal number concentration $N_{\mathrm{i}, \text { single }}$, which is calculated as fol- lows:

$N_{\mathrm{i}, \text { single }}=\sum N_{\mathrm{i}, j}, j \in\{\mathrm{HOM}$, DU, DU-COATED, PREEX, $\}$

where $N_{\mathrm{i}, j}$ are the multi-modal ice crystal number concentrations of each specific ice mode - HOM, DU, DU-COATED, and PREEX.

Figure 1 illustrates how the multi-modal cirrus scheme performs for different initial aerosol and pre-existing ice crystal concentrations in a box model.

The box model does not allow for settling in a column; it only includes nucleation and depositional growth. The increase in temperature due to latent heat is taken into account, but not the change in updraught velocity (Kärcher et al., 2006), which is prescribed as $20 \mathrm{~cm} \mathrm{~s}^{-1}$ in the box model simulations.

A summary of the aerosol and ice initial conditions is given in Table 1. The temporal evolutions of the supersaturation with respect to ice $\left(S_{\mathrm{i}}\right), w_{\text {ice }}$ and the newly formed ICNC are shown. In the case of pure homogeneous freezing (cf. Fig. 1 first row, simulation HOM), the supersaturation increases steadily with time until the critical supersaturation needed for homogeneous nucleation $\left(S_{\mathrm{cr}, \text { hom }}\right)$ is exceeded and ice crystals form from solution droplets. Driven by the choice of initial conditions the number concentration of newly formed ice crystals is approximately $700 \mathrm{~L}^{-1}$. Both formation and depositional growth of these ice crystals lead to a rapid consumption of the available water vapour and a decreasing $S_{\mathrm{i}}$ directly after the freezing event. In this case, the freezing event represented by the dotted line coincides with the peak $S_{\mathrm{i}}$ represented by the dashed line. The peak $S_{\mathrm{i}}$ illustrates the point in time when $S_{\mathrm{i}}$ starts to decrease caused by an efficient consumption of water vapour, i.e. when $w_{\text {ice }}$ exceeds $w$. (Note: when homogeneous nucleation takes place, $w$ is set to zero in order to calculate the effect of these ice crystals without further cooling.)

The second row of Fig. 1 shows a case in which heterogeneous and homogeneous nucleation compete for the available water vapour (simulation COMP1). When $S_{\mathrm{cr}, \mathrm{DU}}$ is exceeded pure dust aerosols act as deposition nuclei and form ice crystals. We prescribe the initial concentration of pure dust aerosols to be $0.001 \mathrm{~cm}^{-3}$. All pure dust aerosols form ice crystals, but their take-up of water vapour is too small to shut off the other nucleation mechanisms and $w_{\text {ice }}$ remains below $w$. Thus, $S_{\mathrm{cr}, \mathrm{DU}-\mathrm{COATED}}$ is exceeded and furthermore the coated dust aerosols nucleate ice crystals. The number concentration of newly formed ice crystals rises to $2 \mathrm{~L}^{-1}$. The fictitious downdraught representing the effect of the growth of these ice crystals on supersaturation does not exceed the prescribed constant updraught of $20 \mathrm{~cm} \mathrm{~s}^{-1}$, such that $S_{\mathrm{i}}$ continues to rise and homogeneous freezing also takes place. The number of homogeneously formed ice crystals is smaller compared to the pure homogeneous freezing case because the heterogeneously formed ice crystals have already consumed part of the available water vapour and less water vapour remains for homogeneous freezing of solution 

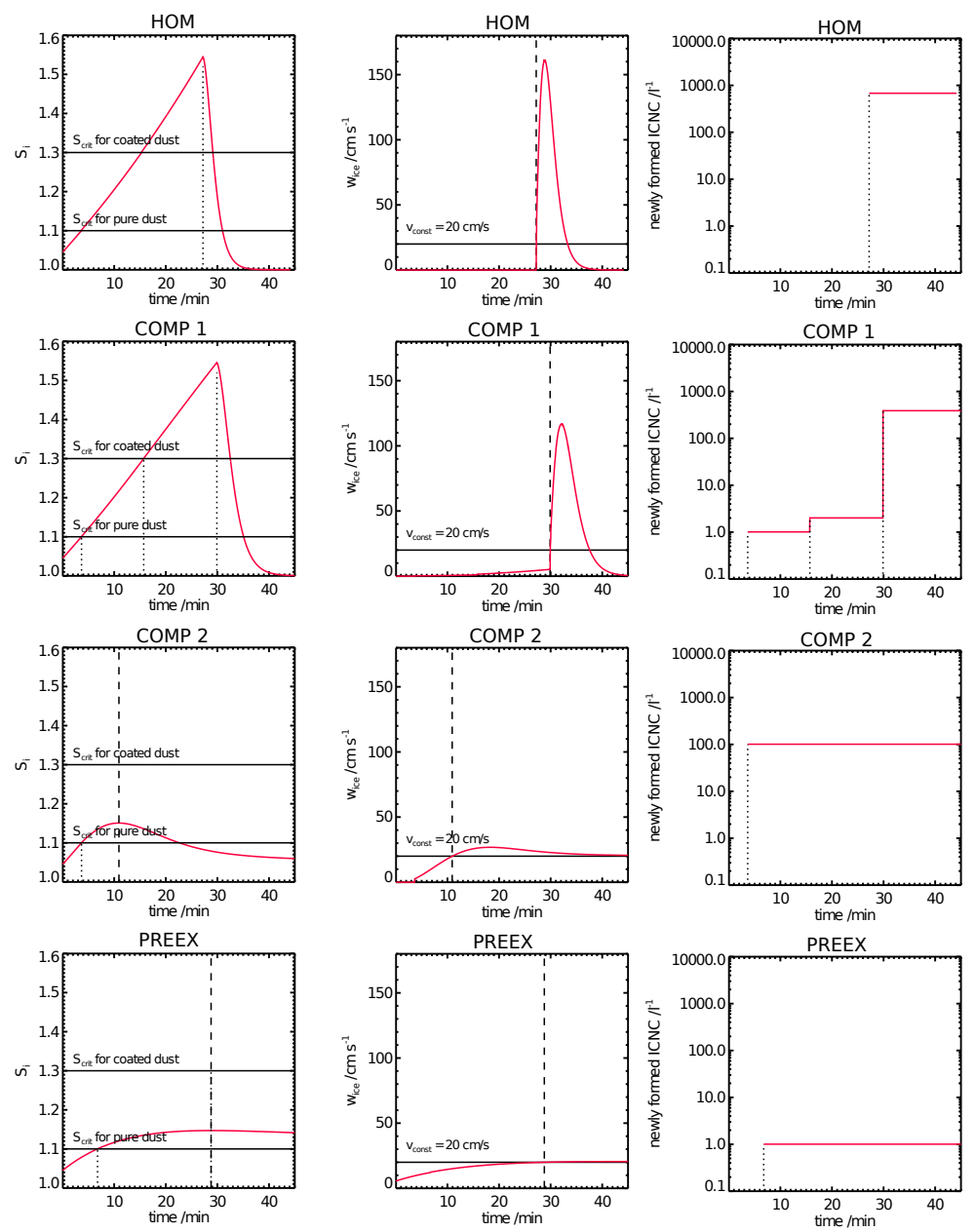

Fig. 1. Temporal evolution of the $S_{\mathrm{i}}, w_{\text {ice }}$ and newly formed ICNC as simulated by the multi-modal ice nucleation scheme used as a box model for simulation HOM (upper row), COMP1 (second row), COMP2 (third row) and PREEX (last row). Initial conditions are $p=100 \mathrm{hPa}, T=210 \mathrm{~K}, S_{\mathrm{i}}=1.2$, and $w=20 \mathrm{~cm} \mathrm{~s}^{-1}$. Initial conditions of aerosol properties and pre-existing ice are given in Table 1 . The dotted line indicates the ice nucleation events and the dashed line indicates the peak $S_{\mathrm{i}}$.

Table 1. Overview over initial conditions of pre-existing ice crystals $\left(N_{\mathrm{i}}, R_{\mathrm{i}}\right)$ and the different aerosol types $\left(N_{\mathrm{a}}, R_{\mathrm{a}}\right)$ of simulations shown in Fig. 1.

\begin{tabular}{l|rr|rr|rr|rr}
\hline & $\begin{array}{r}N_{\mathrm{i}, \text { PREEX }} \\
{\left[\mathrm{L}^{-1}\right]}\end{array}$ & $\begin{array}{r}R_{\mathrm{i}, \text { PREEX }} \\
{[\mu \mathrm{m}]}\end{array}$ & $\begin{array}{r}N_{\mathrm{a}, \mathrm{DU}} \\
{\left[\mathrm{cm}^{-3}\right]}\end{array}$ & $\begin{array}{r}R_{\mathrm{a}, \mathrm{DU}} \\
{[\mu \mathrm{m}]}\end{array}$ & $\begin{array}{r}N_{\mathrm{a}, \text { DU-COATED }} \\
{\left[\mathrm{cm}^{-3}\right]}\end{array}$ & $\begin{array}{r}R_{\mathrm{a}, \text { DU-COATED }} \\
{[\mu \mathrm{m}]}\end{array}$ & $\begin{array}{r}N_{\mathrm{a}, \text { HOM }} \\
{\left[\mathrm{cm}^{-3}\right]}\end{array}$ & $\begin{array}{r}R_{\mathrm{a}, \mathrm{HOM}} \\
{[\mu \mathrm{m}]}\end{array}$ \\
\hline HOM & 0 & 0 & 0 & 0 & 0 & 0 & 500 & 0.05 \\
COMP1 & 0 & 0 & 0.001 & 0.5 & 0.001 & 0.5 & 500 & 0.05 \\
COMP2 & 0 & 0 & 0.1 & 0.5 & 0.001 & 0.5 & 500 & 0.05 \\
PREEX & 10 & 50 & 0.001 & 0.5 & 0.001 & 0.5 & 500 & 0.05 \\
\hline
\end{tabular}

droplets in the competitive case. In this setup of initial conditions, deposition nucleation and immersion freezing of dust aerosols reduces the overall number of newly formed ice crystals. This effect has been termed the "negative Twomey effect" (Kärcher and Lohmann, 2003). However, the heterogeneous nucleation of dust particles is not able to shut off homogeneous freezing, and because homogeneous freezing leads to high ICNC, the change in the newly formed ICNC is rather small.

A case in which homogeneous freezing is shut off is presented in the third row of Fig. 1 (simulation COMP2). Here, the number concentration of pure dust aerosols is enhanced to $0.1 \mathrm{~cm}^{-3}$. When $S_{\mathrm{i}}$ reaches $S_{\mathrm{cr}, \mathrm{DU}}$ all pure dust aerosols form ice crystals. These ice crystals efficiently deplete the 
water vapour such that $w_{\text {ice }}$ exceeds $w$. In this case both immersion freezing of coated dust aerosols and homogeneous freezing are shut off. The point in time when $w_{\text {ice }}$ exceeds $w$ and the overall supersaturation starts decreasing follows about $7 \mathrm{~min}$ after the first pure dust particles nucleated. This shows that the depletion of water vapour takes longer compared to the two cases where homogeneous freezing is involved. This can be explained by the fact that heterogeneous nucleation is limited by the number of aerosols, whereas homogeneous freezing is usually not, except for the tropics, where cirrus clouds under certain conditions might be susceptible to such limitations (Lohmann et al., 2003).

Ice crystal growth depends inversely on size, implying that many homogeneously formed ice crystals grow faster and deplete $S_{\mathrm{i}}$ more readily than only a few heterogeneously formed ice crystals. Also, the supersaturation does not approach saturation within the depicted time frame of $45 \mathrm{~min}$. It can be seen that $w_{\text {ice }}$ converges towards $w$. Only a slight increase in vertical velocity would be sufficient to increase $S_{\mathrm{i}}$ and trigger further ice formation events. On the other hand, a slight decrease in vertical velocity would bring $S_{\mathrm{i}}$ to saturation or even sub-saturation. This points to one limitation of that cirrus scheme, namely the assumption of a constant updraught throughout the whole cirrus ice formation event.

The last row of Fig. 1 illustrates the influence of preexisting ice on the formation of newly formed ice crystals (simulation PREEX). We assume that $N_{\mathrm{i}, \mathrm{PREEX}}=10 \mathrm{~L}^{-1}$ of size $R_{\mathrm{i}, \mathrm{PREEX}}=50 \mu \mathrm{m}$ are present in the grid box before the cirrus scheme is called.

As a first step, the water vapour uptake of the pre-existing ice crystals is calculated by estimating the fictitious downdraught $w_{\text {ice }}$ of these ice crystals (the calculation of $w_{\text {ice }}$ follows Eq. 13 of Kärcher et al., 2006). Then, the scheme checks whether $w_{\text {ice }}$ is already exceeding the constant updraught of $20 \mathrm{~cm} \mathrm{~s}^{-1}$.

The existence of the pre-existing ice is the reason why $w_{\text {ice }} \neq 0 \mathrm{~cm} \mathrm{~s}^{-1}$ at the first time step (different from the other three rows). Since $w_{\text {ice }}<w$ the supersaturation rises and deposition nucleation of pure dust aerosols takes place. We prescribe the number of pure dust aerosols to be $0.001 \mathrm{~cm}^{-3}$, e.g. the lower value which was also used in the competitive case (second row). Together with the pre-existing ice crystals, these heterogeneously formed ice crystals consume the water vapour efficiently and shut off immersion freezing of coated dust aerosols as well as homogeneous freezing. Furthermore, $S_{\mathrm{i}}$ does not approach saturation here and $w_{\text {ice }} \approx w$, indicating a rather slow depletion process.

The last two cases (high pure dust number concentration and pre-existing ice present) shut off homogeneous freezing and thus lead to a significantly reduced overall ICNC compared to the pure homogeneous case. If we account for the number of pre-existing ice crystals in addition to the newly formed ice crystals, then we find ICNC $=100 \mathrm{~L}^{-1}$ and $\mathrm{ICNC}=11 \mathrm{~L}^{-1}$ for the third and fourth row, respectively. Comparing that to the pure homogeneous freez- ing case, where ICNC $=700 \mathrm{~L}^{-1}$ shows that both high IN concentration and the existence of pre-existing ice with low number concentrations can lead to a strong negative Twomey effect and thus change significantly the microphysical properties of cirrus clouds.

\subsubsection{Heterogeneous nucleation of pure and coated mineral dust aerosols}

The ice nucleation ability of mineral dust has been examined in several laboratory-based studies (see review by Hoose and Möhler, 2012). However, many of these studies were only performed for warmer temperatures and only apply to mixed-phase cloud conditions (i.e. $T>T_{\text {hom }}$, where $T_{\text {hom }}=$ $238 \mathrm{~K})$.

In general, and based on these laboratory studies, dust is considered as a good IN since the supersaturation where freezing starts $\left(S_{\mathrm{cr}}\right)$ for pure dust particles varies between 1.01 and 1.35 depending on dust type and particle size (Hoose and Möhler, 2012, and references therein). This is a significantly lower $S_{\mathrm{i}}$ compared to homogeneous freezing. For coated dust particles the spread between the different measurements is larger; $S_{\mathrm{cr}}$ varies between 1.15 and 1.7 and in some cases even exceeds $S_{\text {cr,hom. Different coating ma- }}$ terials and coating thicknesses explain the larger spread in these measurements (Hoose and Möhler, 2012, and references therein).

We conclude that both pure dust and coated dust particles can initiate heterogeneous nucleation in cirrus clouds but that pure dust is the better IN.

Several studies have reported that not all dust aerosols act as IN and initiate ice crystal formation during a nucleation event. In order to describe the ice nucleation ability of any aerosol type, this fraction of activated particles $\left(f_{\mathrm{a}}\right)$ should be taken into account in addition to $S_{\mathrm{cr}}$. We base the description of deposition nucleation of pure dust and immersion freezing of coated dust in the new cirrus scheme on Möhler et al. (2006) and Möhler et al. (2008), respectively. The advantages of these two studies over other studies are the following: first, their measurements are performed at temperatures well below $T_{\text {hom }}$, and for pure dust aerosols a broad range of temperatures is covered; second, they parameterized $f_{\mathrm{a}}$ for use in global climate models; and third, for consistency, we decided to base our assumptions about heterogeneous nucleation for both pure and coated dust aerosols on the same laboratory device.

Möhler et al. (2006) investigated the ice nucleation ability of pure dust aerosols in the AIDA cloud and aerosols chamber in Karlsruhe. Arizona test dust (ATD), which is a rather arbitrary dust sample, and two more natural dust samples from the Taklamakan desert in western China and the Sahara were used as IN. The aerosol size varied between 300 and $500 \mathrm{~nm}$ and the temperature ranged between 196 and $223 \mathrm{~K}$. Based on a large data set they developed the following 
parameterization for $f_{\mathrm{a}}$ :

$f_{\mathrm{a}}=\exp \left(a \cdot\left(S_{i}-S_{\mathrm{cr}, \mathrm{DU}}\right)\right)-1$.

$S_{\mathrm{cr}, \mathrm{DU}}$ and $a$ are fit parameters in this parameterization and need to be taken from the list of measured values given in Möhler et al. (2006). We choose

$S_{\mathrm{cr}, \mathrm{DU}}=1.2 ; a=0.5 \forall 220 \mathrm{~K}<T \leq T_{\text {hom }}$

and

$S_{\mathrm{cr}, \mathrm{DU}}=1.1 ; a=2.0 \forall T \leq 220 \mathrm{~K}$,

which are mean values of the more atmospheric relevant aerosol types from the Sahara and Asian deserts.

Möhler et al. (2008) investigated the ice nucleation ability of coated dust particles. ATD and illite aerosols are coated with semi-volatile products from the reaction of $\alpha$-pinene with ozone in order to mimic atmospheric ageing. The coating mass fraction varies between 17 and $41 \mathrm{wt} \%$. The measurements were also performed in the AIDA chamber and were exposed to temperatures between 201 and $205 \mathrm{~K}$. The general conclusion of that study is that the thicker the coating, the poorer the IN. The maximum $f_{\mathrm{a}}$ reached in this experiment was $0.1-0.2$ and $S_{\mathrm{cr} \text {,DU-COATED }} \approx 1.3$ for ATD particles with a thin coating. The knowledge and measurements of immersion freezing of coated dust aerosols is more limited than for deposition nucleation of pure dust aerosols. We therefore decide to use a rather rough description for immersion freezing of coated dust aerosols in ECHAM5. We choose $f_{\mathrm{a}}=0.05$ and $S_{\text {cr,DU-COATED }}=1.3$ in order to describe immersion freezing of all coated dust aerosols independently of their coating thickness.

\subsection{Setup of simulations}

In the following sections we discuss different aspects concerning the new cirrus scheme incorporated into the ECHAM5-HAM GCM. We start by evaluating the role of homogeneous vs. heterogeneous nucleation and the climatic effects induced by heterogeneous IN and pre-existing ice. For this purpose we have performed the simulations HOM, COMP, HOM+PREEX and HOM+HET (cf. Table 2).

- HOM: only homogeneous freezing takes place. Heterogeneous ice nucleation and pre-existing ice crystals are not considered. This simulation represents the original cirrus scheme implemented in ECHAM5-HAM.

- COMP: homogeneous and heterogeneous nucleation as well as depositional growth of pre-existing ice compete for the available water vapour. Deposition nucleation of pure dust aerosols starts at $S_{\mathrm{cr}}=1.1$ or 1.2 depending on $T$. The activated fraction $f_{\mathrm{a}}$ is parameterized following Möhler et al. (2006). For immersion freezing of coated dust aerosols, $S_{\mathrm{cr}}$ is 1.3 and $f_{\mathrm{a}}$ is $5 \%$. This is the new cirrus scheme as described in Sect. 2.2.
- HOM+PREEX: homogeneous freezing and depositional growth of pre-existing ice crystals compete for the available water vapour. Heterogeneous nucleation is not considered.

- HOM+HET: homogeneous and heterogeneous nucleation compete for the available water vapour. Deposition nucleation of pure dust aerosols starts at $S_{\mathrm{cr}}=1.1$ or 1.2 depending on $T . f_{\mathrm{a}}$ is parameterized following Möhler et al. (2006). For immersion freezing of coated dust aerosols, $S_{\text {cr }}$ is 1.3 and $f_{\mathrm{a}}$ is $5 \%$.

In Sect. 4, we compare the results derived by ECHAM5HAM with the new cirrus scheme with observations. Here we again use the simulations HOM, COMP, HOM+PREEX and HOM+HET. All simulations are run over 5 years in a horizontal resolution of $\mathrm{T} 42\left(2.8125^{\circ} \times 2.8125^{\circ}\right)$ with 19 vertical levels as well as with climatological sea surface temperature and sea ice extent.

\section{Results}

\subsection{Role of homogeneous vs. heterogeneous nucleation}

In this section we examine the simulation COMP, where homogeneous freezing, deposition nucleation of pure dust and immersion freezing of coated dust aerosols and pre-existing ice crystals compete for the available water vapour during ice nucleation and depositional growth. We analyse the four different ice modes in detail in order to understand the role of homogeneous vs. heterogeneous nucleation. These ice modes are as follows:

- PREEX: pre-existing ice crystals from the last time step and ice crystals formed by nucleation processes other than heterogeneous and homogeneous nucleation in cirrus clouds;

- DU: deposition nucleation of pure dust particles;

- DU-COATED: immersion freezing of coated dust particles;

- HOM: homogeneous freezing of liquid solution droplets.

Figure shows annual and zonal means of the ice crystal number concentration ICNC in the cloudy part of the grid box; the ice crystal size $R_{\mathrm{i}}$; and the number concentration of aerosols initiating ice nucleation $N_{\mathrm{a}}$ in the first, second and third column, respectively. The information is given for each individual ice mode. $N_{\mathrm{a}}$ describes the number concentration of heterogeneous IN in the case of DU, and DUCOATED, and of solution droplets in the case of HOM. In Sect. 2.2.1 we further discussed that only a fraction of all aerosols present in a nucleation event acts as IN and introduced the term activated fraction $\left(f_{\mathrm{a}}\right)$. The variable $N_{\mathrm{a}}$ 

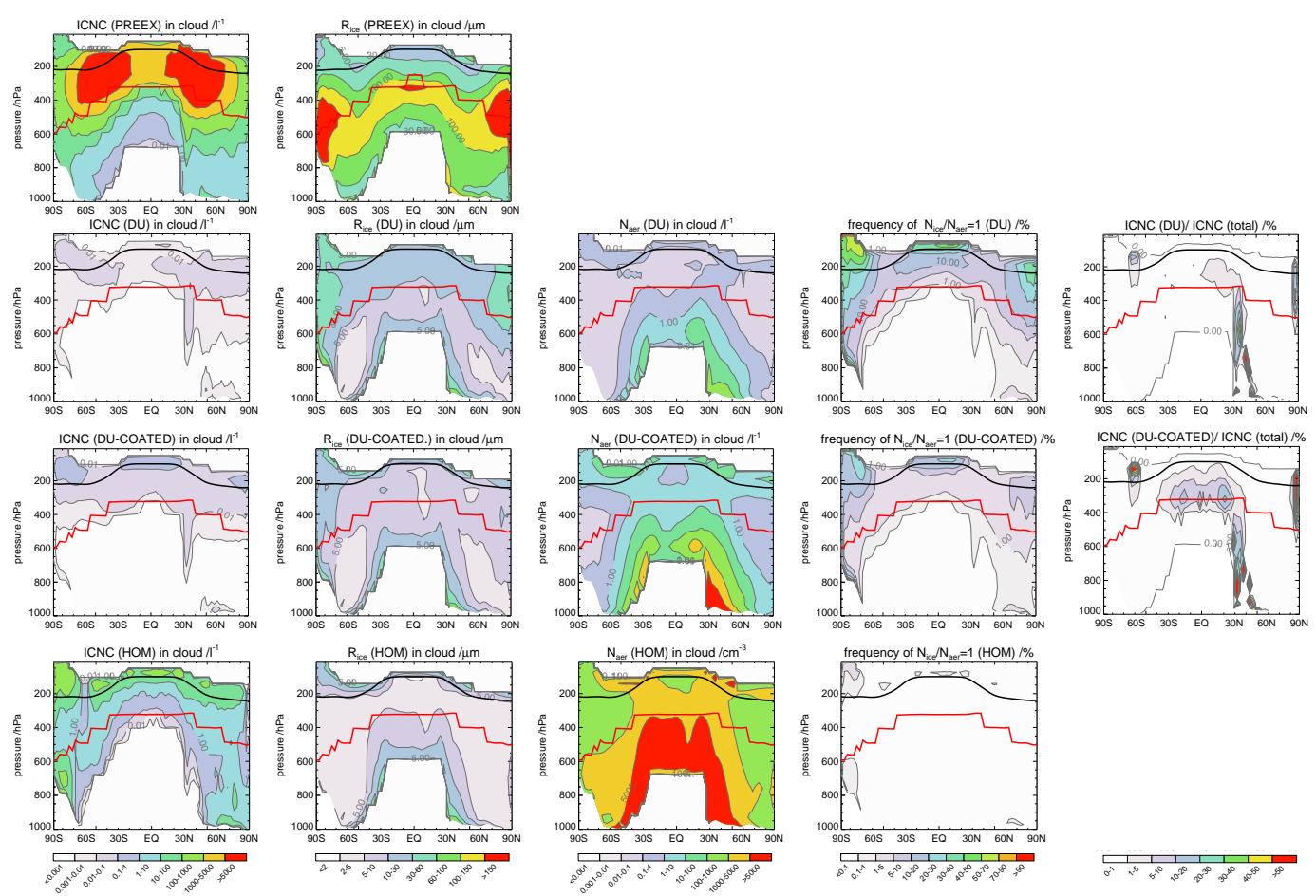

Fig. 2. Annual zonal means of ICNC (first column), the particle size before the larger particles are transferred to snow $R_{\mathrm{i}}$ (second column), the number concentration of heterogeneous IN (in the case of DU, and DU-COATED) and of solution droplets (in the case of HOM) $N_{\mathrm{a}}$ (third column), the percentage frequency of $N_{\mathrm{i}} / N_{\mathrm{a}}=1$ (fourth column) and the fraction of heterogeneously formed ICNC divided by all newly nucleated ICNC (fifth column) for the different ice modes - PREEX, DU, DU-COATED and HOM - inside the cloudy part of the grid box. Note that $N_{\mathrm{a}}$ is given in $\mathrm{L}^{-1}$ in the case of heterogeneous nucleation and in $\mathrm{cm}^{-3}$ in the case of homogeneous freezing. The black line shows the annual mean tropopause and the red line illustrates the mean position of the $-35^{\circ} \mathrm{C}$ isotherm.

Table 2. Overview over simulations. We show which of the four ice modes - PREEX, DU, DU-COATED and HOM - are active in each simulations, as well as the details of heterogeneous ice nucleation. The notations "parameterized 1 " and "parameterized ${ }^{2}$ " mean that $f_{\mathrm{a}, \mathrm{DU}}$ and $S_{\mathrm{cr}, \mathrm{DU}}$ are parameterized according to Eq. (4); and $f_{\mathrm{a}, \mathrm{DU}-\mathrm{COATED}}=0.05$ and $S_{\mathrm{cr}, \mathrm{DU}-\mathrm{COATED}}=1.3$, respectively.

\begin{tabular}{l|l|l|l|l}
\hline & PREEX & DU & DU-COATED & HOM \\
\hline HOM & no & no & no & yes \\
COMP & yes & yes (parameterized & yes parameterized $\left.^{2}\right)$ & yes \\
HOM+PREEX & yes & no & no & yes \\
HOM+HET & no & yes (parameterized & yes parameterized $\left.^{2}\right)$ & yes \\
\hline
\end{tabular}

shown in Fig. 2 takes this activated fraction into account and only shows the part of dust aerosols acting as IN. In the case of HOM, $N_{\mathrm{a}}$ constitutes all internally mixed aerosols except particles with dry radii smaller than $5 \mathrm{~nm}$. Depicted in the fourth column is the fraction of time steps fulfilling the condition $\frac{N_{\mathrm{i}}}{N_{\mathrm{a}}}>0.99$ divided by all time steps during which clouds have been present. $N_{\mathrm{i}}$ represents the ice particle number concentration of the respective ice mode. This quantity provides information as to how often the ice nucleation event is limited by the availability of heterogeneous IN or solution droplets. The fifth column depicts the fraction $\frac{N_{i}}{N_{\mathrm{i}, \text { total }}}$, where $N_{\mathrm{i}, \text { total }}$ is the sum of all freshly nucleated ICNC, e.g. $N_{\mathrm{i}, \text { total }}=N_{\mathrm{i}, \mathrm{DU}}+N_{\mathrm{i}, \mathrm{DU}-\mathrm{COATED}}+N_{\mathrm{i}, \mathrm{HOM}}$. This fraction shows the importance of heterogeneous nucleation compared to homogeneous freezing and where it matters most.

Comparing the ice crystal number concentrations of the different ice modes shows that most ice crystals are contained in PREEX. This does not imply that cirrus clouds are mostly composed of ice crystals stemming from processes other than homogeneous and heterogeneous nucleation at $T<T_{\text {hom }}$ such as detrainment from deep convective clouds or freezing in mixed-phase clouds; rather, it shows that the ice mode PREEX, includes all ice crystals from previous time steps, whereas the other three ice modes only represent the freshly nucleated ice crystals. Ice crystals which formed in the ice mode HOM, at time step $t-1$, are part of ice mode 
PREEX, at time step $t$. This is true for DU and DU-COATED as well. In the two heterogeneous ice modes the lowest ice crystal number concentrations are found with a maximum ICNC of $0.1-1 \mathrm{~L}^{-1}$. Ice crystals formed homogeneously are 3 orders of magnitude higher in number and reach a maximum ICNC of $100-1000 \mathrm{~L}^{-1}$.

This difference in ICNC is caused by the number of available aerosols acting as IN for heterogeneous nucleation or as solution droplets initiating homogeneous freezing (see $N_{\mathrm{a}}$ in the third column of Fig. 2). The number concentration of heterogeneous IN is much smaller compared to the number of solution droplets available for homogeneous freezing. Pure dust particles are only rarely found in the upper troposphere and $N_{\mathrm{a}, \mathrm{DU}}$ ranges between 0.01 and $1 \mathrm{~L}^{-1}$. Approximately 1 order of magnitude more coated dust particles are found and the number concentration of solution droplets is increased by 5 orders of magnitude ranging between $1 \times 10^{5}$ and $5 \times 10^{6} \mathrm{~L}^{-1}$.

Homogeneous freezing is rarely limited by the availability of solution droplets. This is consistent with $N_{\mathrm{a}, \mathrm{HOM}}>$ $N_{\mathrm{i}, \mathrm{HOM}}$. We also see in the fourth column of Fig. 2 that the formation of ice crystals via homogeneous freezing is only limited in $0.1-1 \%$ of all cases. Heterogeneous nucleation is, however, limited by the number concentration of IN. Figure 2 shows that heterogeneous nucleation is limited by the availability of heterogeneous IN in up to $\sim 30 \%$ of all ice formation events in the case of DU-COATED, and in $\sim 70 \%$ in the case of DU. This means that we expect $N_{\mathrm{i}, \mathrm{DU}}$ and $N_{\mathrm{i}, \mathrm{DU}-\mathrm{COATED}}$ close to be equal to $N_{\mathrm{a}, \mathrm{DU}}$ and $N_{\mathrm{a}, \mathrm{DU}-\mathrm{COATED}}$, respectively, which is indeed the case in our results. Areas where cirrus cloud formation is limited by heterogeneous IN are mainly found in the uppermost tropical cirrus and in the Southern Hemisphere (SH). These are regions where generally low IN concentration are present because the main dust sources such as the Sahara and Asian deserts are located in the Northern Hemisphere (NH).

The second column of Fig. 2 shows the ice crystals' radius of each ice mode before the ice crystals larger $100 \mu \mathrm{m}$ are transformed into snow. The largest ice crystals are found in the ice mode PREEX, and the smallest in HOM. Ice crystals of the ice mode PREEX are largest because they represent ice crystals from the last time step which have already grown. Secondly, the new cirrus scheme takes the depositional growth of pre-existing ice crystals into account, which affects the temporal evolution of the supersaturation. Only if the vertical updraught is strong enough to allow $S_{\mathrm{i}}$ to exceed the nucleation thresholds despite its reduction due to pre-existing ice will heterogeneous and homogeneous freezing take place. This means that depositional growth of the pre-existing ice crystals and the formation of new ice crystals are subsequent processes and that the ice mode PREEX is exposed to supersaturation for a longer time than the other three ice modes. For the three freshly nucleated ice crystal types, the following relationship holds: the ice crystal size decreases with increasing critical supersaturation required to initiate freezing (DU, DU-COATED, HOM) because the supersaturation required to nucleate DU is more often exceeded than the supersaturation required to nucleate DUCOATED and HOM. Thus they have more time to grow via depositional growth. Secondly, the ice crystal size is anticorrelated with the aerosol number concentration $N_{\mathrm{a}}$. For a given supersaturation (this means for a fixed amount of water vapour which can be transformed into the solid phase) larger (smaller) ice crystals will form if the aerosol number concentration and thus the ice crystal concentration is low (high).

The fifth column of Fig. 2 shows the fraction of heterogeneously formed ice crystals compared to the total number of freshly nucleated ice crystals. We can see that, in terms of the ice crystal number concentration, cirrus formation is dominated by homogeneous freezing in the tropical uppermost troposphere everywhere but in the $\mathrm{SH}$ around $60^{\circ} \mathrm{S}$ and in the Arctic. All other regions' heterogeneous nucleation contributes to $<5 \%$ of the total number of newly formed ice crystals. The contribution from heterogeneous nucleation is larger in the case of DU-COATED than in the case of DU, because we find more coated dust particles in the upper troposphere compared to pure dust aerosols leading to more $\mathrm{ICNC}_{\mathrm{DU}-\mathrm{COATED}}$ than $\mathrm{ICNC}_{\mathrm{DU}}$. Heterogeneous nucleation contributes largest in the lower tropical troposphere and in the Arctic. Here, the contributions reach $30 \%$ and partly even exceed $30 \%$ for DU-COATED.

Liu et al. (2012) found similar results: heterogeneous nucleation contributes most in the lower tropical troposphere and in the $\mathrm{NH}$, with values exceeding $50 \%$. In the upper troposphere they found only weak contributions of heterogeneous nucleation of less than $10 \%$ or less than $1 \%$ depending on the nucleation scheme. The main difference between the results of Liu et al. (2012) and ours are the mid-latitudes in the NH. While our results suggest that heterogeneous nucleation does not play an important role there, Liu et al. (2012) conclude that in this region (together with the lower tropical troposphere), the largest contributions from heterogeneous nucleation can be found. These differences may either be caused by the cirrus scheme or by the initial aerosol number concentration. The dust concentration presented in Liu et al. (2012) shows more dust aerosols in the NH with concentrations 1 order of magnitude lower in the SH throughout the troposphere. This difference between $\mathrm{NH}$ and $\mathrm{SH}$ is much weaker in our IN number concentrations depicted in Fig. 2. One should keep in mind that we take the activated fraction (see Table 2 and Eq. 4) into account in Fig. 2 and only show the IN active fraction of all pure dust or coated dust particles. Thus, the number concentration of all pure dust aerosols has a different zonal distribution. One important difference between our cirrus scheme and the nucleation schemes used by Liu et al. (2012) is that we account for the depositional growth of pre-existing ice crystals during the freezing event. The pre-existing ice affects the rate of heterogeneously and homogeneously formed ice crystals (Hendricks et al., 2011; Kärcher et al., 2006), and thus it is likely 
that the consideration of the pre-existing ice might change the percentage contribution of heterogeneous nucleation.

Figure 3 shows the global distributions of heterogeneous IN concentrations and of the resulting ice crystal number concentrations averaged between 130 and $270 \mathrm{hPa}$. Both ice modes DU, and DU-COATED, are taken into account. Please note the different colour bars in both panels. We can see that highest IN concentrations of $20-50 \mathrm{~L}^{-1}$ are found over northern Africa, the North Atlantic Ocean, northern parts of South America and central Asia. The IN concentrations include pure and coated dust particles and it makes sense that highest dust concentrations are found near the main dust sources such as Asian deserts and the Sahara. Wiacek et al. (2010) showed that dust aerosols lifted up into the upper troposphere originate from Asian deserts rather than from the Sahara. Also our model suggests that maximum IN concentrations exceeding $50 \mathrm{~L}^{-1}$ between 130 and $270 \mathrm{hPa}$ are close to Asian deserts. The Saharan Air Layer is represented reasonably well, covering the region over the North Atlantic Ocean between the Sahara and the American continent (Prospero and Carlson, 1972; Dunion and Velden, 2004). Studies about IN measurements in the upper troposphere are sparse because accurate measurements of IN in the field remain challenging (DeMott et al., 2011). DeMott et al. (2003) performed a campaign at Storm Peak Laboratory in Colorado, USA, with direct access to free-tropospheric air. They measured cirrus ice crystal residuals and found IN concentrations of less than $30 \mathrm{~L}^{-1}$. During the SUCCESS campaign, the typical IN concentration was found to be of the order of $10 \mathrm{~L}^{-1}$ (Rogers et al., 1998). IN concentrations simulated by ECHAM5-HAM with the new cirrus scheme vary between 5 and $20 \mathrm{~L}^{-1}$ in most parts of the globe and are thus in good agreement with the observational results by DeMott et al. (2003).

The sum of both heterogeneously formed ice crystal number concentrations between 130 and $270 \mathrm{hPa}$ varies between 0.1 and $10 \mathrm{~L}^{-1}$. These values are slightly smaller than the IN concentrations in the same pressure levels, indicating that either the heterogeneously formed ice crystals sediment to lower levels due to their large sizes, and thus high sedimentation velocities, or that not all IN freeze to ice crystals as discussed above. As expected, we can see that regions of high $\mathrm{ICNC}_{\text {het }}$ coincide with regions of high IN concentrations. This shows that the formation of heterogeneously formed ice crystals is strongly dependent on the IN concentration and thus on the assumptions made about the activated fraction in order to diagnose the IN concentration from the total dust concentrations.

\subsection{Climatic effects}

In this section we analyse the effects of heterogeneous nucleation and the consideration of pre-existing ice on climate. In order to do so, we compare the following simulations HOM, COMP, HOM+PREEX and HOM+HET (cf. Table 2).
Figure 3.2 shows annual and zonal means of the vertically integrated ice crystal number concentration $\left(\mathrm{ICNC}_{\text {burden }}\right)$, the vertically integrated ice water content (ice water path, IWP), total cloud cover (TCC), and the short-wave and longwave cloud forcings (SCF, LCF) for the different simulations. If possible, we also included observations from different sources in the plots. $\mathrm{ICNC}_{\text {burden }}$ is significantly reduced in the tropics and the mid-latitudes of the $\mathrm{NH}$ in COMP compared to HOM. In these regions $\mathrm{ICNC}_{\text {burden }}$ is reduced by $\sim 15 \%$. No regions exist where $\mathrm{ICNC}_{\text {burden }}$ is enhanced in COMP. Heterogeneous nucleation and pre-existing ice reduce the overall ICNC, because they consume water vapour, which in the case of HOM would have been available for homogeneous freezing and would thus decrease or even suppress homogeneous freezing in the case of COMP. The negative Twomey effect as introduced by Kärcher and Lohmann (2003) in a detailed microphysical box model can thus be represented in the GCM (Hendricks et al., 2011). The positive Twomey effect was found to be of minor importance in Kärcher et al. (2006) and thus plays a negligible role in the GCM. Also, Hendricks et al. (2011) found reductions in ICNC which were mostly pronounced in the tropics and midlatitudes.

The simulation HOM+PREEX and HOM+HET help to understand the reductions in ICNC in more detail: ICNC of simulation HOM+HET follows simulation HOM in the tropics but deviates in the mid-latitudes of the $\mathrm{NH}$, whereas simulation HOM+PREEX is close to COMP everywhere. This shows that the depositional growth of pre-existing ice crystals in the tropics is mostly responsible for the reductions in ICNC and that heterogeneous IN seem to play only a minor role. However, heterogeneous IN significantly reduce ICNC in the mid-latitudes of the $\mathrm{NH}$ via the abovementioned negative Twomey effect in the absence of preexisting ice (HOM+HET vs. HOM). If pre-existing ice is present, then the Twomey effect is much weaker (COMP vs. HOM+PREEX).

In the $\mathrm{SH}$ no changes are found between the simulations HOM and COMP. We have seen in Sect. 3.1 that the IN concentrations are larger in the $\mathrm{NH}$ than in the $\mathrm{SH}$ because of the location of the main dust sources, and thus the largest changes in $\mathrm{ICNC}_{\text {burden }}$ between HOM+HET and HOM are found in NH mid-latitudes. This result is in good agreement with Liu et al. (2012), who found the largest IN-induced effects on ICNC also in NH mid-latitudes. The largest changes in the tropics stem from considering pre-existing ice.

IWP is reduced in the same regions as $\mathrm{ICNC}_{\text {burden }}$ when we account for competitive ice nucleation and depositional growth despite the increase in ice crystals' size in COMP. The decrease in IWP shows that the loss in ice mass induced by fewer ice crystals cannot be compensated for by increasing ice crystal size. Furthermore, here, the changes in IWP in the tropics seem to be driven by the depositional growth of pre-existing ice, whereas heterogeneous IN cause the changes in the $\mathrm{NH}$ mid-latitudes. 

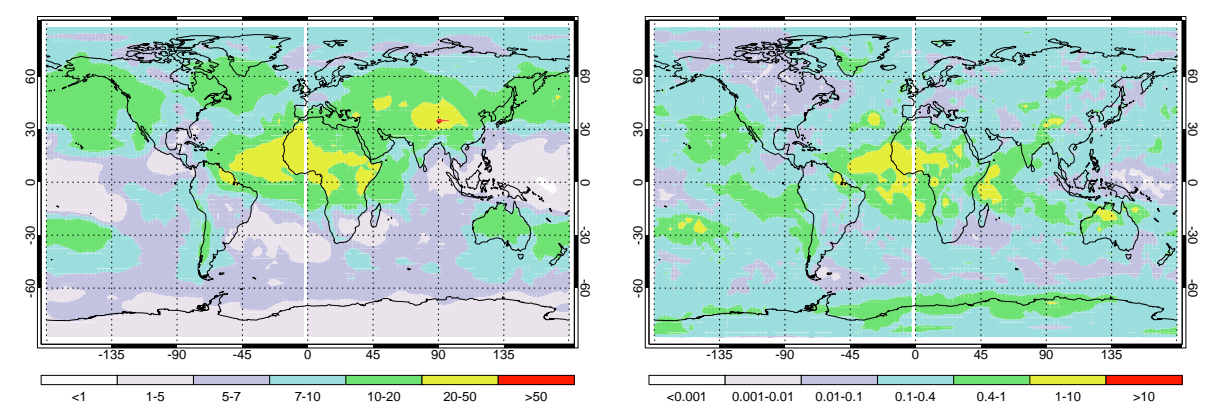

Fig. 3. Left: IN concentration $(130-270 \mathrm{hPa}) \mathrm{L}^{-1}$. Right: $\mathrm{ICNC}_{\text {het }}(130-270 \mathrm{hPa}) \mathrm{L}^{-1}$. Annual mean global distributions of heterogeneous IN concentrations $\left(N_{\mathrm{a}, \mathrm{DU}}+N_{\mathrm{a}, \mathrm{DU}-\mathrm{COATED}}\right)$ in $\mathrm{L}^{-1}$ and of the resulting ice crystal number concentrations $\left(N_{\mathrm{i}, \mathrm{DU}}+N_{\mathrm{i}, \mathrm{DU}-\mathrm{COATED}}\right)$ in $\mathrm{L}^{-1}$ averaged between 130 and $270 \mathrm{hPa}$. Note the different colour bars.

The total cloud cover is only affected slightly by heterogeneous nucleation and pre-existing ice crystals. We see small differences in the tropics, but no changes in the NH midlatitudes. This was also observed by Liu et al. (2012). Heterogeneous IN decrease the high cloud cover through fewer and larger ice crystals, which sediment faster, but may lead to increased cloud cover below. The change in TCC is therefore difficult to interpret. Figure 5 shows the differences in zonal mean cloud cover as a function of pressure and latitude for the simulations COMP, HOM+PREEX and HOM+HET as compared to HOM. We see that pre-existing ice decreases the cirrus cloud cover mostly in the tropics and at high latitudes by up to $6 \%$. The changes in cirrus cloud cover induced by heterogeneous IN are negligible. The consideration of preexisting ice crystals which are large in size (cf. also Fig. 2) and sediment fast seems to not only influence cirrus cloud cover but also reduces the total cloud cover in the tropics, where cirrus clouds constitute an important fraction of TCC. The observations of TCC are based on three different satellite products and show a large spread. The spread between our simulations is smaller. In all simulations ECHAM5-HAM fits the observations in the mid-latitudes and tropics, but underestimates TCC in the subtropics and overestimates TCC at high latitudes.

The short- and long-wave cloud forcings show different changes between the simulations COMP and HOM. The SCF is affected only slightly and only in the tropics. Here the SCF becomes less negative by $\sim 3 \mathrm{~W} \mathrm{~m}^{-2}$ when heterogeneous nucleation and pre-existing ice is taken into account. Changes in SCF coincident with regions of changes in TCC imply that SCF is strongly dependent on TCC. Preexisting ice crystals reduce cirrus cloud cover, as explained above, and thus allow more SW radiation to enter the Earthatmosphere system. The reduction in $\mathrm{ICNC}_{\text {burden }}$ in the $\mathrm{NH}$ mid-latitudes combined with no changes in TCC does not lead to strong changes in the SCF. This is different for LCF. Here changes in the tropics and the $\mathrm{NH}$ mid-latitudes can be observed. LCF decreases by $\sim 4.5 \mathrm{~W} \mathrm{~m}^{-2}$ in the tropics and $\sim 2 \mathrm{~W} \mathrm{~m}^{-2}$ in the $\mathrm{NH}$ mid-latitudes when heterogeneous nucleation and pre-existing ice competes with homogeneous freezing. Cirrus clouds with fewer and larger ice crystals and a reduced ice mass trap less outgoing LW radiation. Additionally, when heterogeneous nucleation takes, place cirrus clouds can form at lower altitudes, because only smaller supersaturations are required to initiate heterogeneous nucleation, in contrast to homogeneous freezing. Cirrus clouds at lower altitudes absorb and re-emit $\mathrm{LW}$ radiation at warmer $T$ compared to the case of HOM. Since the LCF is dependent on the difference between $T$ at the surface and $T$ of the cirrus cloud, which becomes smaller in the case of COMP, the LCF also decreases. The comparison to observations shows again that the spread in the different satellite products is larger than the spread between our simulations. Generally, our simulations match the observations, except in the subtropics for the SCF and in the mid-latitudes for the LCF.

The above discussion shows that both heterogeneous IN and pre-existing ice have the potential to significantly impact cirrus clouds and the energy budget with regional differences: heterogeneous IN seem to be the main driver for the simulated climate perturbations in the $\mathrm{NH}$ mid-latitudes and pre-existing ice is the most important driver in the tropics. This difference is plausible if one considers that the two regions (tropics, NH mid-latitudes) are characterized by differences in the variables which mostly drive indirect effects in cirrus clouds (such as vertical velocity, temperature and IN number concentration).

Table 3 shows the annual and global mean precipitation $(P)$, total cloud cover TCC, aerosol optical depth (AOD), water path of liquid and ice (LWP, IWP), vertically integrated number concentration of cloud droplets and ice crystals $\left(\mathrm{CDNC}_{\text {burden }}, \mathrm{ICNC}_{\text {burden }}\right)$, effective ice crystal radius $\left(R_{\text {eff, }}\right)$, short-wave and long-wave cloud forcings (SCF, LCF) and the top-of-atmosphere (TOA) net radiation $\left(F_{\text {net }}\right)$ for the simulations HOM and COMP. Additionally, the differences of these annual and global means as well as the percentage difference between COMP and HOM are given. We see strong changes in the percentage differences in $\mathrm{ICNC}_{\text {burden. }}$. When heterogeneous nucleation and 

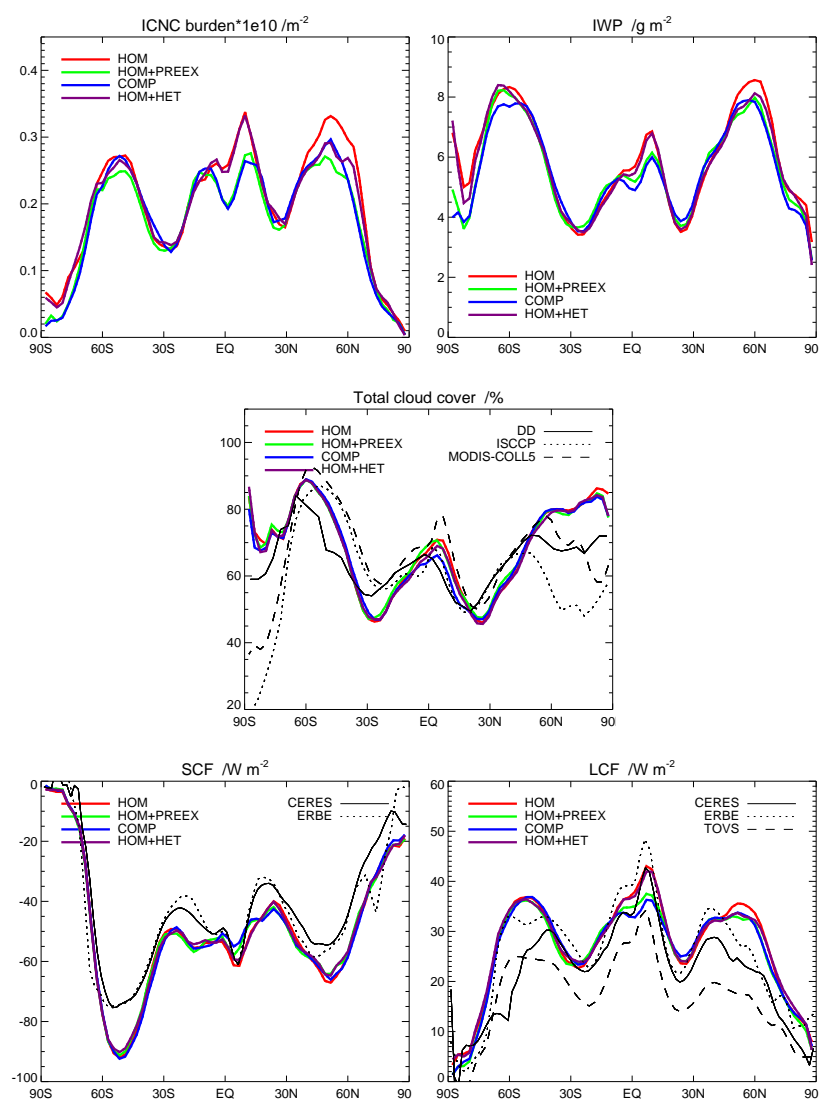

Fig. 4. Annual and zonal means of ICNC burden, IWP, TCC, SCF and LCF for the different simulations HOM, COMP, $\mathrm{HOM}+\mathrm{PREEX}$ and HOM+HET. The following satellite-based observations are used: CERES, Clouds and Earth's Radiant Energy System (Wielicki et al., 1996); ISCCP, International Satellite Cloud Climatology Project (Han et al., 1998); MODIS-COLL5, Moderate Resolution Imaging Spectroradiometer, Collection 5 (http:// modis-atmos.gsfc.nasa.gov/products.html); ERBE, Earth Radiation Budget Experiment (https://science.larc.nasa.gov/erbe); and TOVS, TIROS Operational Vertical Sounder (Scott et al., 1999). DD represents surface observations of the total cloud cover (Hahn et al., 1994).

pre-existing ice crystals compete with homogeneous freezing, $\mathrm{ICNC}_{\text {burden }}$ is globally reduced by $10 \%$. This shows that heterogeneous nucleation on dust and pre-existing ice can consume the available water vapour efficiently and reduce the homogeneous nucleation rate. This implies that competitive ice nucleation mechanisms can have a significant global impact on the microphysical properties of cirrus clouds. Liu et al. (2012) also found global reductions of $\mathrm{ICNC}_{\text {burden }}$ of $1-17 \%$ depending on the cirrus nucleation scheme used.

The global mean effective ice crystal radius is increased by $3 \%$. We have seen in Sect. 3.1 that the ice modes PREEX, DU and DU-COATED have larger ice crystal sizes compared to the ice mode HOM. This is caused by the length of time the ice crystals are exposed to supersaturation and by the aerosol number concentration. The ice water path is globally reduced by $5 \%$. This is in agreement with Liu et al. (2012), who found reductions of $0-4.6 \%$ depending on the nucleation scheme. The decrease in IWP and the increase in LWP are not as pronounced as the decrease in $\mathrm{ICNC}_{\text {burden }}$. The change in $\mathrm{ICNC}_{\text {burden }}$ between HOM and COMP results from a reduction in $\mathrm{ICNC}_{\mathrm{HOM}}$ and an increase in $\mathrm{ICNC}_{\mathrm{DU}}$ and $\mathrm{ICNC}_{\mathrm{DU}-\mathrm{COATED}}$. This means that in the case of COMP, we expect a decrease of small ice crystals and a slight increase of large ice crystals. The ice mass represented by IWP is therefore affected by two counteracting changes: an increase in IWP due to slightly more large ice crystals and a reduction in IWP due to much fewer small ice crystals. The reduction in the number of homogeneously formed ice crystals and the increase in heterogeneously formed ice crystals together result in an increase of $R_{\text {eff,i }}$ of $3 \%$.

The total cloud cover is globally decreased by $4 \%$. We have already discussed that TCC is difficult to interpret and we have seen that cirrus cloud cover is regionally reduced by $6 \%$. Generally, we found that pre-existing ice consists of large ice crystals, which sediment faster to lower altitudes and warmer temperatures where they evaporate. The effect on global TCC in our result is higher than in the study of Liu et al. (2012), who found values of $0.2 \%$. Precipitation changes only slightly between the simulations COMP and HOM.

These global changes in microphysical properties of cirrus clouds affect the radiation budget of the Earth-atmosphere system. SCF is enhanced by $0.95 \mathrm{~W} \mathrm{~m}^{-2}$ and LCF is decreased by $1.5 \mathrm{~W} \mathrm{~m}^{-2}$. The $\mathrm{SW}$ effect is caused by a reduced cloud albedo which in turn is caused by reduced TCC, reduced $\mathrm{ICNC}_{\text {burden }}$, larger $R_{\text {eff, } \mathrm{i}}$ and reduced IWP. Less SW radiation is scattered back to space and more SW radiation enters the Earth-atmosphere system. Fewer cirrus clouds with fewer and larger ice crystals and less ice mass trap less LW radiation and thus lead to a decrease in LCF. Globally the LW effects dominated over the SW effects, such that the Earth-atmosphere system is exposed to a net cloud forcing of $-0.55 \mathrm{~W} \mathrm{~m}^{-2}$. The changes in the clear-sky radiation amount to $-0.4 \mathrm{~W} \mathrm{~m}^{-2}$ due to cooling by less water vapour, and thus the impact of heterogeneous IN and pre-existing ice causes the Earth-atmosphere system to cool by $0.94 \mathrm{~W} \mathrm{~m}^{-2}$ in the net all sky radiation at TOA.

The differences in global mean all sky radiation between simulation HOM+HET and HOM as well as HOM+PREEX and $\mathrm{HOM}$ are $-0.02 \mathrm{~W} \mathrm{~m}^{-2}$ and $-1.02 \mathrm{~W} \mathrm{~m}^{-2}$, respectively. This shows that in terms of global mean values the consideration of preexisting ice plays the most important role and that considering heterogeneous nucleation of dust in addition to homogeneous nucleation is rather negligible. However, as stated above (cf. Fig. and corresponding text), on a regional scale both microphysical processes are important and either one can dominate, and thus need to be considered for cirrus cloud modelling. 


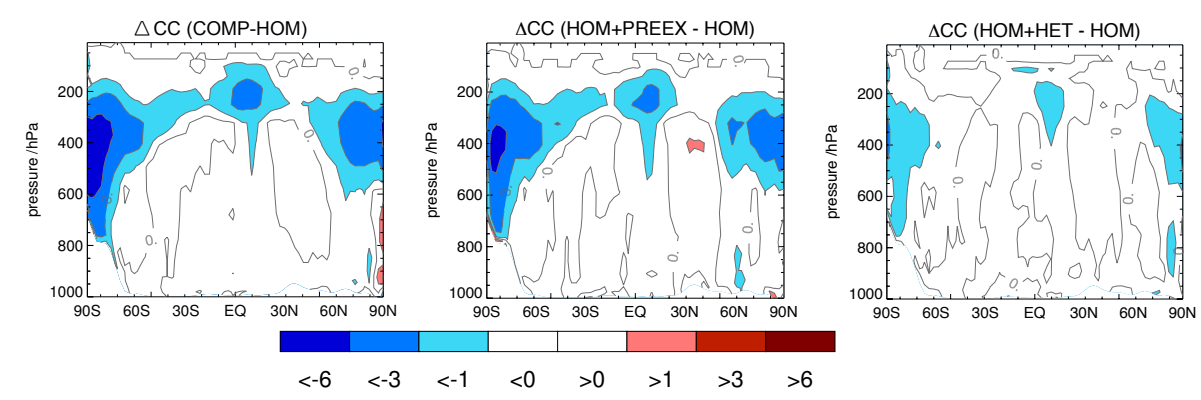

Fig. 5. Annual and zonal mean differences of cloud cover as a function of pressure and latitude for the different simulations COMP, $\mathrm{HOM}+\mathrm{PREEX}$ and $\mathrm{HOM}+\mathrm{HET}$ compared to HOM.

Table 3. Global multi-annual (10-year) mean cloud properties and TOA energy budget for the simulations HOM and COMP.

\begin{tabular}{ll|rrrr}
\hline & & HOM & COMP & Difference COMP-HOM & Relative change [\%] \\
\hline$P_{\text {tot }}$ & {$\left[\mathrm{mm} \mathrm{d}^{-1}\right]$} & 2.83 & 2.87 & 0.04 & 1 \\
TCC & {$[\%]$} & 64.5 & 62.3 & -2.3 & -4 \\
LWP & {$\left[\mathrm{g} \mathrm{m}^{-2}\right]$} & 55.7 & 55.6 & 0.08 & -1 \\
IWP & {$\left[\mathrm{g} \mathrm{m}^{-2}\right]$} & 5.4 & 5.1 & -0.3 & -5 \\
$\mathrm{CDNC}_{\text {burden }}$ & {$\left[1 \times 10^{10} \mathrm{~m}^{-2}\right]$} & 2.6 & 2.61 & 0.01 & $<1$ \\
$\mathrm{ICNC}_{\text {burden }}$ & {$\left[1 \times 10^{10} \mathrm{~m}^{-2}\right]$} & 0.22 & 0.2 & -0.022 & -10 \\
$R_{\text {eff,i }}$ & {$\left[\mu \mathrm{m}^{-2}\right]$} & 14 & 14.45 & 0.45 & 3 \\
$\mathrm{SCF}$ & {$\left[\mathrm{W} \mathrm{m}^{-2}\right.$} & -55.8 & -54.8 & 0.95 & -2 \\
$\mathrm{LCF}$ & {$\left[\mathrm{W} \mathrm{m}^{-2}\right]$} & 30.3 & 28.8 & -1.5 & -5 \\
$F_{\text {net }}$ & {$\left[\mathrm{W} \mathrm{m}^{-2}\right]$} & 0.34 & -0.61 & -0.94 & -280 \\
\hline
\end{tabular}

Liu et al. (2012) found a net cloud forcing of $-0.3 \mathrm{~W} \mathrm{~m}^{-2}$ when IN concentrations of $20-50 \mathrm{~L}^{-1}$ were used, similar to our IN concentrations. In the case of IN concentrations of $200 \mathrm{~L}^{-1}$ their net cloud forcing was $-0.4 \mathrm{~W} \mathrm{~m}^{-2}$, composed, however, of large SCF and LCF of $2 \mathrm{~W} \mathrm{~m}^{-2}$ and $-2.4 \mathrm{~W} \mathrm{~m}^{-2}$, respectively.

Liu et al. (2012) only present zonal means and show that the LW and SW changes occur in the tropics $\left(10^{\circ} \mathrm{S}-10^{\circ} \mathrm{N}\right)$ and in mid-latitudes of both hemispheres and that they are offsetting each other in the same regions.

\subsection{Comparison with observations}

In this part we validate the model simulations against different observational data sets. We compare the four simulations $\mathrm{HOM}, \mathrm{HOM}+\mathrm{HET}, \mathrm{HOM}+\mathrm{PREEX}$ and COMP, which are described in Sect. 2.3, with airborne in situ data from several field campaigns (Krämer et al., 2009).

\subsubsection{In-cloud ICNC}

Figure 6 shows ICNC in cirrus clouds vs. $T$. The observational data stem from airborne in situ measurements derived from 9.7 sampling hours during 28 flights. The field campaigns were performed between 1999 and 2006 and cover the Arctic, mid-latitudes and tropics between $75^{\circ} \mathrm{N}$ and $30^{\circ} \mathrm{S}$ (Krämer et al., 2009). The observed data of ICNC vs. $T$ vary over a large range, indicated by the light-grey shaded area representing the $0-100$ th percentile. We additionally show the 25-75th percentile (dark-grey shaded area). The model results are based on 6-hourly output data for January, April, July and October. The solid lines represent the median of the simulated ICNC and the dotted lines the mean of ICNC. The huge spread between median and mean indicates that the distribution of ice crystals is skewed. In a skewed distribution the mean is sensitive to outliers and thus not robust. We therefore concentrate on the median in the following comparison.

The observed ICNC shows an increase with increasing $T$ and the 25-75th percentiles of ICNC vary between about 0.01 and $10 \mathrm{~cm}^{-3}$. The observational range between maximum and minimum ICNC is large. Minimum ICNC of $0.002 \mathrm{~cm}^{-3}$ and maximum ICNC of $60 \mathrm{~cm}^{-3}$ can be found. The fewest ice crystals are found in very cold cirrus below $200 \mathrm{~K}$. Krämer et al. (2009) mention possible explanations for this: ice nucleation might be suppressed by the incorporation of organic material (Murphy et al., 2007) or ice nucleation might be dominated by heterogeneous nucleation, shutting off homogeneous freezing. A third possibility is homogeneous freezing at only very low vertical updraughts. Krämer et al. (2009) argue that one of the first two explanations is the most likely because in the upper troposphere/lower stratosphere region (UTLS) higher vertical updraught has been reported (Lawson et al., 2008). One open 

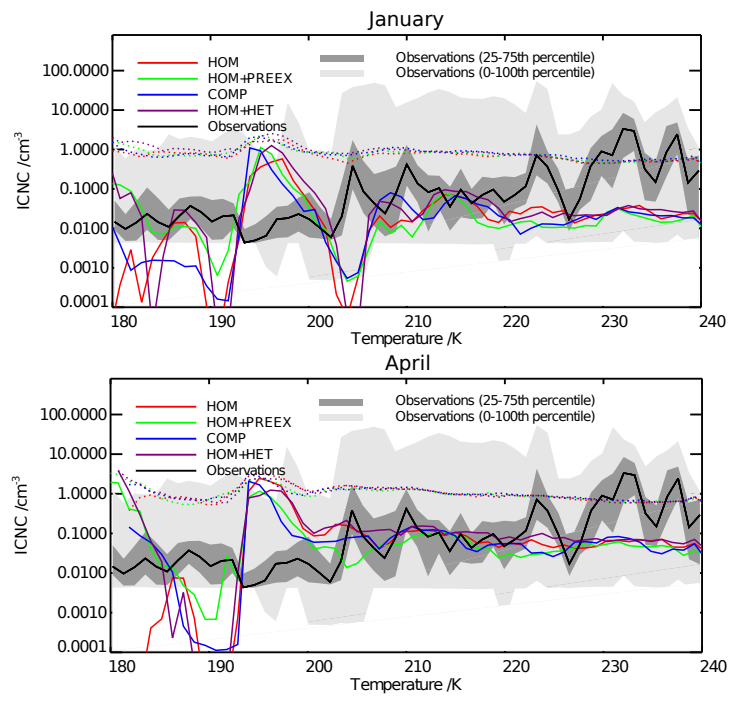

July
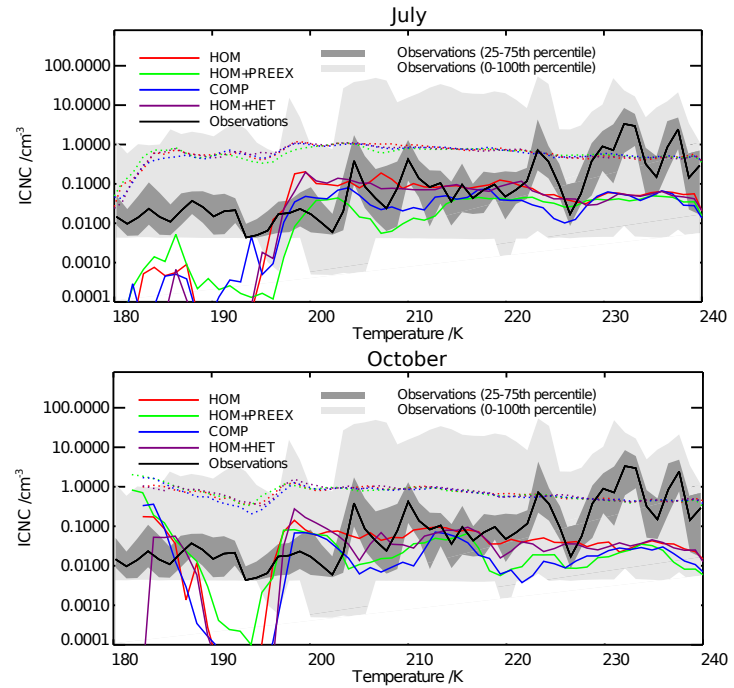

Fig. 6. Median (solid) and mean (dotted) of ICNC inside of cirrus vs. $T$ for the simulations HOM, HOM+PREEX, COMP and $\mathrm{HOM}+\mathrm{HET}$. Model results are sampled every $6 \mathrm{~h}$ for January, April, July and October of the year 2000. All data are sorted into $1 \mathrm{~K} T$ bins. Airborne in situ measurements are shown in grey shaded areas.

question, however, is still to what extent heterogeneous nucleation can dominate the ice nucleation in the UTLS.

The vertical velocities in cirrus regions from ECHAM were compared in Kärcher and Ström (2003). The probability density function (PDF) of vertical velocities in ECHAM matches the observed data from the INCA campaign very well with an average of $31 \mathrm{~cm} \mathrm{~s}^{-1}$ as compared to $26 \mathrm{~cm} \mathrm{~s}^{-1}$, but only if turbulent fluctuations based on TKE (Eq. 1) are included.

Since these observations are based on Forward Scattering Spectrometer Probe (FSSP) measurements (de Reus et al., 2009), the reported ice crystal number concentrations might be influenced by shattering. Shattering of ice crystals on the inlet of the FSSP becomes more important in warm cirrus, where ice crystals are typically larger and play only a minor role in cold cirrus clouds (Field et al., 2003, 2006a). For the following comparison of our model simulations with observations we should keep in mind that in warm cirrus clouds, the measured ice crystal number concentration might be overestimated.

The simulations HOM, HOM+PREEX, HOM+HET and COMP lie mostly between the observational range. Figure 6 shows that there are rather small changes between the different simulations for warmer $T$, but we can see significant differences between the simulations for colder $T$. This might indicate that heterogeneous nucleation plays a stronger role in cold cirrus clouds than in warm cirrus clouds. We would like to reiterate that global mean $\mathrm{ICNC}_{\text {burden }}$ changes by $-10 \%$ and global mean $R_{\text {eff,i }}$ changes by $3 \%$ between HOM and COMP, as shown in Sect. 3.2. Our analysis revealed that heterogeneous nucleation contributes significantly to these differences.

For $T>220 \mathrm{~K}$ all simulations underestimate ICNC and suggest a comparatively stable median of ICNC at $0.01-$ $0.06 \mathrm{~cm}^{-3}$. The 25-75th percentile of the observed ICNC varies strongly in this temperature range and is 1 to 2 orders of magnitude higher than the simulated median. For cold cirrus clouds $(T<205 \mathrm{~K})$ the spread between different simulations is large, as is the spread of ICNC within one simulation. For most months the simulation HOM+PREEX fits the observations slightly better and the simulations COMP, $\mathrm{HOM}+\mathrm{HET}$ and HOM underestimate ICNC. However, the spread in simulated ICNC within one simulation is large and thus it is difficult to judge which simulation is closest to observations. For example, in April, all simulations show very small ICNC of $0.001-0.0001 \mathrm{~cm}^{-3}$ for $185<T<193 \mathrm{~K}$ and high ICNC of $1 \mathrm{~cm}^{-3}$ for $194<T<200 \mathrm{~K}$, whereas the observed 25-75th percentile only varies between 0.01 and $0.1 \mathrm{~cm}^{-3}$.

Generally, all simulations, except for cold cirrus clouds, are in the observational range. The simulated median, however, frequently falls below the observed $25-75$ th percentile, suggesting that all simulations underestimate ICNC within cirrus clouds. Also, the pure homogeneous simulation does not produce a sufficiently high number concentration of ice crystals to match the observed ICNC. This might indicate that ECHAM5-HAM generally underestimates the rate of homogeneously formed ice crystals. Since homogeneous freezing is mainly dependent on vertical velocity and temperature, this comparison might hint at a bias in $T$ or $w$. However, the simulations underestimate ICNC for every $T$ bin. Thus we believe that the vertical velocity in ECHAM5-HAM in the cirrus cloud level might be too low. The vertical velocity is parameterized using the turbulent kinetic energy and the gravity wave drag. It might, however, be reasonable to use an even more complex vertical velocity scheme such as a statistical PDF approach. Our results further suggest that effects 
of heterogeneous IN and pre-existing ice become more important at cold cirrus rather than in warm cirrus.

Liu et al. (2012), Gettelman et al. (2012), Wang and Penner (2010) and Salzmann et al. (2010) also compared ICNC simulated by their models with different cirrus nucleation schemes with the observational data set of Krämer et al. (2009). Contrary to ECHAM5-HAM, all the other models overestimate ICNC compared to observations. The model of Liu et al. (2012) showed best agreement of ICNC at low $T$ with observations if pure heterogeneous nucleation was assumed. However, this simulation did not fit the observations for warmer $T$. They concluded that homogeneous freezing is the prevailing process in warmer cirrus clouds above $205 \mathrm{~K}$ and that homogeneous freezing might be suppressed at very low $T$. A possible reason for the suppression of homogeneous freezing at cold $T$ is the incorporation of organic material into aerosols transforming the aerosols into a glassy state which prevents homogeneous freezing (Murray, 2008).

The lower ice crystal number concentrations predicted by ECHAM5-HAM at low temperatures agree with a new study by Spichtinger and Krämer (2012), explaining low observed ice crystal concentrations in the TTL with the consideration of the complex dynamics as well as homogeneous nucleation and the competition of homogeneous and heterogeneous nucleation. They found that low ICNC can be statistically explained $80 \%$ through homogeneous nucleation and $20 \%$ through a competition of heterogeneous and homogeneous nucleation in an environment with very slow large-scale ascents and superimposed high-frequency gravity waves.

In addition, the lowest measured ice crystal number concentrations are limited by the sensitivity of the FSSP; thus lower concentrations could be possible (Spichtinger and Krämer, 2012). In light of these two findings, our low ice crystal concentrations might be plausible.

\subsubsection{In-cloud $\mathrm{RH}_{\mathrm{i}}$}

Figure 7 shows the frequency of occurrence of $\mathrm{RH}_{\mathrm{i}}$ within cirrus clouds vs. $T$. The observations are based on the same data set as in Fig. 6. We compare the simulations HOM, HOM+PREEX, HOM+HET and COMP of 6-hourly output with these airborne in situ measurements. All data are sorted into $1 \mathrm{~K} T$ bins. The observations show that $\mathrm{RH}_{\mathrm{i}}$ within cirrus clouds varies over a large range from $50 \%$ in the subsaturated region to the homogeneous freezing threshold in the supersaturated region. However, most frequent $\mathrm{RH}_{\mathrm{i}}$ values are found at saturation. At $T<200 \mathrm{~K}$ a high frequency of occurrence varies over a broader range around saturation than compared to warmer $T$. With decreasing $T$ the growth respectively sublimation rate of ice crystals is slower, causing the ice crystals to exist at lower subsaturated conditions. At lower $T$, depositional growth is also slower, causing high supersaturations to remain longer (Krämer et al., 2009). $\mathrm{RH}_{\mathrm{i}}$ over the whole $T$ range does not exceed water saturation (except at $T \sim 238 \mathrm{~K}$, where the water saturation is close to the homogeneous freezing threshold.) The observations show only $\mathrm{RH}_{\mathrm{i}}$ values exceeding the homogeneous freezing threshold at $T<200 \mathrm{~K}$. These observations might stem from convective overshooting in the tropics, where cirrus clouds form at high vertical velocities and very low temperatures. Here, nucleation and water vapour depletion due to the formed ice crystals might not be able to compensate for the $\mathrm{RH}_{\mathrm{i}}$ increase caused by the large vertical velocity.

The model results show generally a good agreement with the observations. We clearly see the highest frequencies of occurrence around saturation agreeing with observations. Also, $\mathrm{RH}_{\mathrm{i}}$ is usually below the homogeneous freezing threshold. Differences between model simulations $\mathrm{HOM}, \mathrm{HOM}+\mathrm{PREEX}, \mathrm{HOM}+\mathrm{HET}$ and COMP can be found mainly at warmer temperatures. Here, HOM and $\mathrm{HOM}+\mathrm{HET}$ show too high frequencies of $\mathrm{RH}_{\mathrm{i}}$ at the homogeneous freezing threshold compared to observations. Simulation COMP fits the observations in this temperature regime best, with $\mathrm{RH}_{\mathrm{i}}$ most often around saturation. This shows that the consideration of pre-existing ice and heterogeneous nucleation is required to deplete supersaturations within cirrus clouds as fast and strongly as suggested by observations.

For cold cirrus, however, the model underestimates the frequency of occurrence of supersaturations in all simulations. The measurement data frequently show supersaturations reaching the homogeneous freezing threshold, whereas the model most frequently simulates saturation and only suggests rare occurrences of supersaturations. $\mathrm{RH}_{\mathrm{i}}$ is mostly dependent on ICNC and $w$. Since the model underestimates ICNC in cold cirrus, this might point to a bias in the vertical velocity, as already mentioned above. In the model, the vertical velocity is described by a turbulent kinetic energy scheme extended to account for orographic cirrus clouds which form in the lee of mountains (Lohmann and Kärcher, 2002; Lohmann et al., 2004; Joos et al., 2008). While the agreement of simulated vertical velocity with observations was reasonable, the vertical velocity in model rather erred on the low side and could thus be responsible for the low ICNC. Spichtinger and Krämer (2012) showed that in order to simulate low ICNC with homogeneous and a combination of homogeneous and heterogeneous nucleation, a more complex vertical velocity scheme resolving the complex dynamics in the TTL needs to be applied. This, however, is beyond the scope of this study and will be addressed in future work.

\section{Conclusions}

We incorporated a new cirrus scheme into the GCM ECHAM5-HAM. This cirrus scheme treats nucleation and depositional growth of pre-existing ice, as well as heterogeneously and homogeneously formed ice crystals, in a competitive manner (Kärcher et al., 2006). We distinguish between deposition nucleation of pure dust and immersion freezing of coated dust particles and base our assumptions 

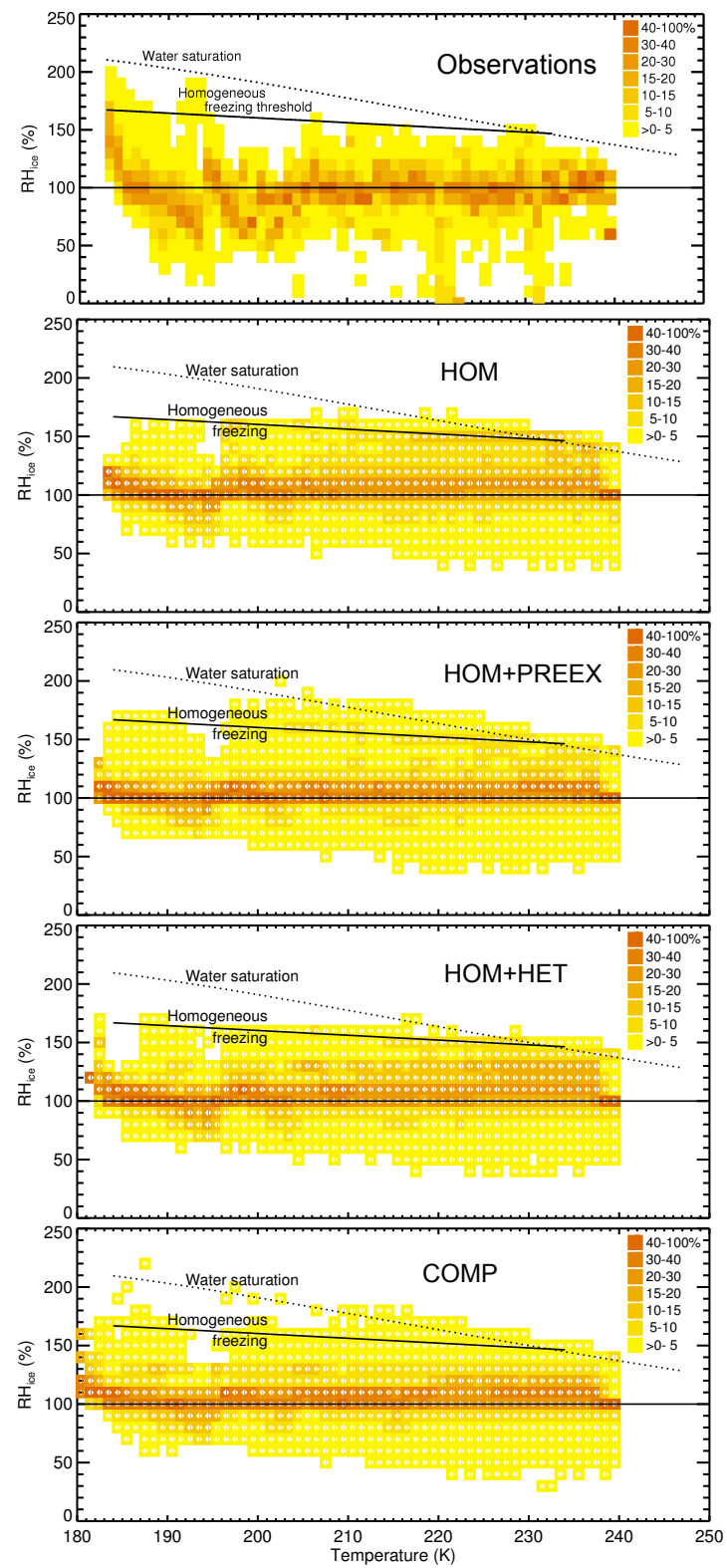

Fig. 7. Frequency of occurrence of $\mathrm{RH}_{\mathrm{i}}$ inside of cirrus vs. $T$. The uppermost panel depicts $9.7 \mathrm{~h}$ of airborne in situ measurements. All other panels show model results of the simulations HOM, HOM+PREEX, HOM+HET and COMP. Model results are sampled every $6 \mathrm{~h}$ for January of the year 2000. All data are sorted into $1 \mathrm{~K} T$ bins. The black solid line indicates the homogeneous freezing threshold and the dotted line represents water saturation $\left(\mathrm{RH}_{\mathrm{W}}=100 \%\right)$.

about freezing threshold $\left(S_{\mathrm{cr}}\right)$ and activated fraction $\left(f_{\mathrm{a}}\right)$ on laboratory data derived by Möhler et al. (2006, 2008). Unlike other studies (Hendricks et al., 2011; Liu et al., 2007, 2009) we did not consider heterogeneous nucleation of soot because the nucleation ability of soot at cirrus relevant temperatures remains uncertain (Kärcher et al., 2007; Hoose and Möhler, 2012). We performed several simulations (see Ta- ble 2) in order to analyse the following aspects of the new cirrus scheme:

- the role of homogeneous vs. heterogeneous nucleation,

- climatic effects of heterogeneous IN and pre-existing ice on cirrus clouds,

- comparison with in situ observations.

We summarize the most important conclusions below:

1. The consideration of heterogeneous nucleation on mineral dust and the depositional growth of preexisting ice in the GCM simulations lead to cirrus clouds composed of fewer and larger ice crystals. Supersaturations are partly or completely depleted by nucleation and depositional growth of pre-existing and heterogeneously formed ice crystals such that homogeneous freezing is weakened or shut off. Our analysis allows for distinguishing between the effect of heterogeneous nucleation and pre-existing ice: the presence of ice crystals prior to a nucleation event can prevent homogeneous and heterogeneous nucleation from occurring due to the depletion of water vapour by depositional growth. The microphysical and radiative changes in the tropics simulated here are mostly driven by this effect of pre-existing ice. On the other hand, changes in the NH mid-latitudes are mostly driven by dust acting as heterogeneous IN. Thus, the so-called negative Twomey effect in cirrus clouds is represented in GCMs.

2. ICNC and $R_{\mathrm{i}}$ of the individual ice modes considered in the model are strongly dependent on two factors: first, the availability of aerosols (IN in the case of heterogeneous nucleation, solution droplets in the case of homogeneous freezing), and second, the time the ice crystals are exposed to supersaturation. Contrary to homogeneous freezing, heterogeneous nucleation is limited by the availability of heterogeneous IN. The simulations reveal that more coated dust particles are present in the UTLS compared to pure dust particles and, consequently, ice crystals formed via deposition nucleation of pure dust are most limited.

3. IN concentrations in the UTLS show reasonable global distributions: highest IN concentrations are found near major dust sources like the Sahara and Asian deserts with IN concentrations of $20-50 \mathrm{~L}^{-1}$. The Saharan Air Layer covering the North Atlantic Ocean between the Sahara and the America continent is also represented reasonably well. Simulated IN concentration vary mostly between 5 and $20 \mathrm{~L}^{-1}$ and agree well with field measurements of ice crystal residuals derived by DeMott et al. (2003). 
4. Heterogeneous nucleation and the consideration of pre-existing ice may lead to significant climatic effects: globally, ice crystal number and mass are reduced by 10 and $5 \%$, whereas the ice crystal size is increased by $3 \%$. The reductions in $\mathrm{ICNC}_{\text {burden }}$ are most pronounced in the tropics and mid-latitudes in the $\mathrm{NH}$, in agreement with Hendricks et al. (2011). The net change in the radiation budget is $-0.94 \mathrm{~W} \mathrm{~m}^{-2}$, implying that heterogeneous nucleation and pre-existing ice induce a cooling to the Earth-atmosphere system. The net cooling is caused by a decrease in LCF in the NH mid-latitudes (mostly caused by heterogeneous nucleation), a decrease in LCF combined with a minor increase in SCF in the tropics (mostly caused by preexisting ice) and a clear-sky cooling due to less water vapour. The results are mainly in agreement with Liu et al. (2012), who based their analysis on the parameterizations of Liu and Penner (2005) and Barahona and Nenes (2009). Differences might arise from other IN schemes used and the fact that we account for preexisting ice.

5. We compare $\mathrm{RH}_{\mathrm{i}}$ and ICNC inside of cirrus of different simulations with in situ observations. Mostly the simulations lie within the observational range and agree with observations. The comparison of ICNC inside of cirrus shows that all simulations underestimate ICNC compared to observations, especially for warm cirrus clouds $(220<T<238 \mathrm{~K})$. However, one should keep in mind that observed ICNC in warm cirrus clouds might be affected by shattering. In this temperature range all simulations show very similar ICNC and heterogeneous nucleation or pre-existing ice does not play an important role in modulating ICNC.

For cold cirrus clouds $(T<205 \mathrm{~K})$ the spread between the different simulations is large, and these simulations either over- or underestimate the observed ICNC. The simulation in which homogeneous freezing only competes with pre-existing ice fits observations best in this temperature range. Liu et al. (2012) concluded that - in order to fit observations - homogeneous freezing dominates in warm cirrus and heterogeneous nucleation becomes important in cold cirrus clouds. Our results point to the same conclusion.

6. Simulated $\mathrm{RH}_{\mathrm{i}}$ inside of cold cirrus is most frequently found at saturation, in agreement with observations. For warm cirrus, simulations neglecting the effects of pre-existing ice on nucleation overestimate the frequency of occurrence of high supersaturations around the homogeneous freezing threshold. In warm cirrus clouds, the simulation COMP fits the observations best, which indicates that both pre-existing ice and heterogeneous nucleation are required in order to deplete supersaturations, as suggested by observations.
In this study we have only analysed the importance of heterogeneous nucleation on cirrus clouds on a global scale. However, local phenomena such as dust outbreaks from the Sahara have been shown to affect European weather (Bangert et al., 2012). ECHAM5-HAM with the new cirrus scheme is suitable to also study possible local/regional effects of heterogeneous nucleation of dust on cirrus clouds. We based our assumptions about heterogeneous nucleation $\left(S_{\mathrm{cr}}, f_{\mathrm{a}}\right)$ on recent laboratory data, and the resulting IN concentrations agree well with observations. However, IN measurements in the UTLS are sparse, and thus a proper validation of our assumptions is hampered. Thus, more field measurements in the UTLS are required to fully constrain the role of heterogeneous nucleation in cirrus clouds and to improve their representation in GCMs.

In addition, the new cirrus scheme still has some shortcomings. For example, if both heterogeneous and homogeneous nucleation occur, the heterogeneously nucleated ice cannot sediment before homogeneous freezing occurs. This could be of importance for small vertical velocities and moderate IN concentrations and could result in too high ice crystal number concentrations. Moreover, the vertical velocity is constant over one model time step. While this is probably uncritical for homogeneous nucleation, in the case of the competition of heterogeneous and homogeneous nucleation it could be important.

Furthermore, the comparison of $\mathrm{RH}_{\mathrm{i}}$ showed that ECHAM might have a bias with too low vertical velocities. The vertical velocity scheme used here already accounts for unresolved vertical velocity fluctuations by using the turbulent kinetic energy as well as for orographic cirrus. However other sources of sub-grid-scale velocity fluctuations, such as convective gravity waves, are missing. They may be needed to also capture the complex dynamics in the TTL.

So far, we have use a simple cloud cover scheme (Sundqvist et al., 1989) based only on relative humidity. In future, this should be replaced by a cloud cover scheme that is consistent with the sub-grid-scale fluctuations in vertical velocity following Kärcher (2012).

Acknowledgements. We would like to acknowledge support from NCCR climate and C2SM. For CPU time, we thank CSCS and DKRZ.

Edited by: M. Krämer

\section{References}

Archuleta, C. M., DeMott, P. J., and Kreidenweis, S. M.: Ice nucleation by surrogates for atmospheric mineral dust and mineral dust/sulfate particles at cirrus temperatures, Atmos. Chem. Phys., 5, 2617-2634, doi:10.5194/acp-5-2617-2005, 2005.

Bangert, M., Nenes, A., Vogel, B., Vogel, H., Barahona, D., Karydis, V. A., Kumar, P., Kottmeier, C., and Blahak, U.: Saharan dust 
event impacts on cloud formation and radiation over Western Europe, Atmos. Chem. Phys., 12, 4045-4063, doi:10.5194/acp-124045-2012, 2012.

Barahona, D. and Nenes, A.: Parameterizing the competition between homogeneous and heterogeneous freezing in ice cloud formation - polydisperse ice nuclei, Atmos. Chem. Phys., 9, 59335948, doi:10.5194/acp-9-5933-2009, 2009.

Cantrell, W. and Heymsfield, A.: Production of Ice in Tropospheric Clouds: A Review., B. Am. Meteorol. Soc., 86, 795-807, doi:10.1175/BAMS-86-6-795, 2005.

Chen, T., Rossow, W. B., and Zhang, Y.: Radiative Effects of CloudType Variations, J. Climate, 13, 264-286, doi:10.1175/15200442(2000)013<0264:REOCTV>2.0.CO;2, 2000.

Cziczo, D. J., Froyd, K. D., Gallavardin, S. J., Moehler, O., Benz, S., Saathoff, H., and Murphy, D. M.: Deactivation of ice nuclei due to atmospherically relevant surface coatings, Environ. Res. Lett., 4, 044013, doi:10.1088/1748-9326/4/4/044013, 2009.

Cziczo, D. J., Froyd, K. D., Hoose, C., Jensen, E. J., Diao, M., Zondlo, M. A., Smith, J. B., Twohy C. H., and Murphy, D. M.: Clarifying the Dominant Sources and Mechanisms of Cirrus Cloud Formation, Science, 340, 1320-1324, 2013.

DeMott, P., Cziczo, D., Prenni, A., Murphy, D., Kreidenweis, S., Thomson, D., Borys, R., and Rogers, D.: Measurements of the concentration and composition of nuclei for cirrus formation., $\mathrm{P}$. Natl. Acad. Sci. USA, 100, 14655-14660, 2003.

DeMott, P. J., Möhler, O., Stetzer, O., Vali, G., Levin, Z., Petters, M. D., Murakami, M., Leisner, T., Bundke, U., Klein, H., Kanji, Z. A., Cotton, R., Jones, H., Benz, S., Brinkmann, M., Rzesanke, D., Saathoff, H., Nicolet, M., Saito, A., Nillius, B., Bingemer, H., Abbatt, J., Ardon, K., Ganor, E., Georgakopoulos, D. G., and Saunders, C.: Resurgence in Ice Nuclei Measurement Research, B. Am. Meteorol. Soc., 92, 1623-1635, doi:10.1175/2011BAMS3119.1, 2011.

de Reus, M., Borrmann, S., Bansemer, A., Heymsfield, A. J., Weigel, R., Schiller, C., Mitev, V., Frey, W., Kunkel, D., Kürten, A., Curtius, J., Sitnikov, N. M., Ulanovsky, A., and Ravegnani, F.: Evidence for ice particles in the tropical stratosphere from in-situ measurements, Atmos. Chem. Phys., 9, 6775-6792, doi:10.5194/acp-9-6775-2009, 2009.

Diehl, K. and Wurzler, S.: Heterogeneous drop freezing in the immersion mode: Model calculations considering soluble and insoluble particles in the drops, J. Atmos. Sci., 61, 2063-2072, 2004.

Diehl, K., Simmel, M. and Wurzler, S.: Numerical simulations on the impact of aerosol properties and freezing modes on the glaciation, microphysics, and dynamics of convective clouds, J. Geophys. Res., 111, D07202, doi:10.1029/2005JD005884, 2006.

Dunion, J. P. and Velden, C. S.: The Impact of the Saharan Air Layer on Atlantic Tropical Cyclone Activity, B. Am. Meteorol. Soc., 85, 353-365, doi:10.1175/BAMS-85-3-353, 2004.

Feichter, J., Kjellström, E., Rodhe, H., Dentener, F., Lelieveld, J., and Roelofs, G.-J.: Simulation of the tropospheric sulfur cycle in a global climate model, Atmos. Environ., 30, 1693-1707, 1996.

Field, P. R., Wood, R., Brown, P. R. A., Kaye, P. H., Hirst, E., Greenaway, R., and Smith, J. A.: Ice Particle Interarrival Times Measured with a Fast FSSP, J. Atmos. Ocean Tech., 20, 249-261, doi:10.1175/1520-0426(2003)020<0249:IPITMW>2.0.CO;2, 2003.

Field, P. R., Heymsfield, A. J., and Bansemer, A.: Shattering and Particle Interarrival Times Measured by Optical Array
Probes in Ice Clouds, J. Atmos. Ocean Tech., 23, 1357-1371, doi:10.1175/JTECH1922.1, 2006a.

Field, P. R., Möhler, O., Connolly, P., Krämer, M., Cotton, R., Heymsfield, A. J., Saathoff, H., and Schnaiter, M.: Some ice nucleation characteristics of Asian and Saharan desert dust, Atmos. Chem. Phys., 6, 2991-3006, doi:10.5194/acp-6-2991-2006, 2006.b.

Fusina, F., Spichtinger, P., and Lohmann, U.: Impact of ice supersaturated regions and thin cirrus on radiation in the midlatitudes, J. Geophys. Res., 112, D24S14, doi:10.1029/2007JD008449, 2007.

Gettelman, A., Liu, X., Barahona, D., Lohmann, U., and Chen, C.: Climate impacts of ice nucleation, J. Geophys. Res., 117, D20201, doi:10.1029/2012JD017950, 2012.

Haag, W. and Kärcher, B.: The impact of aerosols and gravity waves on cirrus clouds at midlatitudes, J. Geophys. Res., 109, D12202, doi:10.1029/2004JD004579, 2004.

Hahn, C. J., Warren, S. G., and London, J.: Climatological data for clouds over the globe from surface observations, 1982-1991: The total cloud edition., Tech. rep., Oak Ridge National Laboratory, 1994.

Han, Q., Rossow, W. B., Chou, J., and Welch, R. M.: Global variation of column droplet concentration in low level clouds, Geophys. Res. Lett., 25, 1419-1422, doi:10.1029/98GL01095, 1998.

Hendricks, J., Kärcher, B., and Lohmann, U.: Effects of ice nuclei on cirrus clouds in a global climate model, J. Geophys. Res., 116, D18206, doi:10.1029/2010JD015302, 2011.

Hoose, C. and Möhler, O.: Heterogeneous ice nucleation on atmospheric aerosols: a review of results from laboratory experiments, Atmos. Chem. Phys., 12, 9817-9854, doi:10.5194/acp-12-98172012, 2012.

Hoyle, C. R., Luo, B. P., and Peter, T.: The origin of high ice crystal number densities in cirrus clouds, J. Atmos. Sci., 62, 2568-2579, 2005.

Jensen, E. J., Smith, J. B., Pfister, L., Pittman, J. V., Weinstock, E. M., Sayres, D. S., Herman, R. L., Troy, R. F., Rosenlof, K., Thompson, T. L., Fridlind, A. M., Hudson, P. K., Cziczo, D. J., Heymsfield, A. J., Schmitt, C., and Wilson, J. C.: Ice supersaturations exceeding $100 \%$ at the cold tropical tropopause: implications for cirrus formation and dehydration, Atmos. Chem. Phys., 5, 851-862, doi:10.5194/acp-5-851-2005, 2005.

Joos, H., Spichtinger, P., Lohmann, U., Gayet, J.-F., and Minikin, A.: Orographic cirrus in the global climate model ECHAM5, J. Geophys. Res., 113, D18205, doi:10.1029/2007JD009605, 2008.

Kärcher, B.: Supersaturation Fluctuations in Cirrus Clouds Driven by Colored Noise, J. Atmos. Sci., 69, 435-443, 2012.

Kärcher, B. and Burkhardt, U.: A Cirrus cloud scheme for general circulation models, Q. J. Roy. Meteorol. Soc., 134, 1439-1461, 2008.

Kärcher, B. and Lohmann, U.: A parameterization of cirrus cloud formation: Homogeneous freezing of supercooled aerosols, J Geophys. Res., 107, 4010, doi:10.1029/2001JD000470, 2002.

Kärcher, B. and Lohmann, U.: A parameterization of cirrus cloud formation: Heterogeneous freezing, J. Geophys. Res., 108, 4402, doi:10.1029/2002JD003220, 2003.

Kärcher, B. and Ström, J.: The roles of dynamical variability and aerosols in cirrus cloud formation, Atmos. Chem. Phys., 3, 823838, doi:10.5194/acp-3-823-2003, 2003.

Kärcher, B., Hendricks, J., and Lohmann, U.: Physically based parameterization of cirrus cloud formation for use in 
global atmospheric models, J. Geophys. Res., 111, D01205, doi:10.1029/2005JD006219, 2006.

Kärcher, B., Möhler, O., DeMott, P. J., Pechtl, S., and Yu, F.: Insights into the role of soot aerosols in cirrus cloud formation, Atmos. Chem. Phys., 7, 4203-4227, doi:10.5194/acp-7-4203-2007, 2007.

Koehler, K. A., Kreidenweis, S. M., DeMott, P. J., Petters, M. D., Prenni, A. J., and Möhler, O.: Laboratory investigations of the impact of mineral dust aerosol on cold cloud formation, Atmos. Chem. Phys., 10, 11955-11968, doi:10.5194/acp10-11955-2010, 2010.

Koop, T., Luo, B., Tsias, A., and Peter, T.: Water activity as the determinant for homogeneous ice nucleation in aqueous solutions, Nature, 406, 611-614, doi:10.1038/35020537, 2000.

Krämer, M., Schiller, C., Afchine, A., Bauer, R., Gensch, I., Mangold, A., Schlicht, S., Spelten, N., Sitnikov, N., Borrmann, S., de Reus, M., and Spichtinger, P.: Ice supersaturations and cirrus cloud crystal numbers, Atmos. Chem. Phys., 9, 3505-3522, doi:10.5194/acp-9-3505-2009, 2009.

Lawson, R. P., Pilson, B., Baker, B., Mo, Q., Jensen, E., Pfister, L., and Bui, P.: Aircraft measurements of microphysical properties of subvisible cirrus in the tropical tropopause layer, Atmos. Chem. Phys., 8, 1609-1620, doi:10.5194/acp-8-1609-2008, 2008.

Levkov, L., Rockel, B., Kapitza, H., and Raschke, E.: 3D mesoscale numerical studies of cirrus and stratus clouds by their time and space evolution., Beitr. Phys. Atmos., 65, 35-58, 1992.

Liu, X. and Penner, J. E.: Ice nucleation parameterization for global models, Meteorol. Z., 14, 499-514, 2005.

Liu, X., Penner, J. E., Ghan, S. J., and Wang, M.: Inclusion of Ice Microphysics in the NCAR Community Atmospheric Model Version 3 (CAM3), J. Climate, 20, 4526-4547, doi:10.1175/JCLI4264.1, 2007.

Liu, X., Shi, X., Zhang, K., Jensen, E. J., Gettelman, A., Barahona, D., Nenes, A., and Lawson, P.: Sensitivity studies of dust ice nuclei effect on cirrus clouds with the Community Atmosphere Model CAM5, Atmos. Chem. Phys., 12, 12061-12079, doi:10.5194/acp-12-12061-2012, 2012.

Liu, X. H., Penner, J. E., and Wang, M. H.: Influence of anthropogenic sulfate and black carbon on upper tropospheric clouds in the NCAR CAM3 model coupled to the IMPACT global aerosol model, J. Geophys. Res., 114, D03204, doi:10.1029/2008JD010492, 2009.

Lohmann, U. and Diehl, K.: Sensitivity Studies of the Importance of Dust Ice Nuclei for the Indirect Aerosol Effect on Stratiform Mixed-Phase Clouds, J. Atmos. Sci., 63, 968-982, doi:10.1175/JAS3662.1, 2006.

Lohmann, U. and Kärcher, B.: First interactive simulations of cirrus clouds formed by homogeneous freezing in the ECHAM general circulation model, J. Geophys. Res, 107, 4105-4118, 2002.

Lohmann, U., Kaercher, B., and Timmreck, C.: Impact of the Mount Pinatubo eruption on cirrus clouds formed by homogeneous freezing in the ECHAM4 GCM, J. Geophys. Res., 108, 4568, doi:10.1029/2002JD003185, 2003.

Lohmann, U., Kärcher, B., and Hendricks, J.: Sensitivity studies of cirrus clouds formed by heterogeneous freezing in the ECHAM GCM, J. Geophys. Res., 109, D16204, doi:10.1029/2003JD004443, 2004.
Lohmann, U., Spichtinger, P., Jess, S., Peter, T., and Smit, H.: Cirrus cloud formation and ice supersaturated regions in a global climate model, Environ. Res. Lett., 3, 045022, doi:10.1088/17489326/3/4/045022, 2008.

Möhler, O., Field, P. R., Connolly, P., Benz, S., Saathoff, H., Schnaiter, M., Wagner, R., Cotton, R., Krämer, M., Mangold, A., and Heymsfield, A. J.: Efficiency of the deposition mode ice nucleation on mineral dust particles, Atmos. Chem. Phys., 6, 30073021, doi:10.5194/acp-6-3007-2006, 2006.

Möhler, O., Benz, S., Saathoff, H., Schnaiter, M., Wagner, R., Schneider, J., Walter, S., Ebert, V., and Wagner, S.: The effect of organic coating on the heterogeneous ice nucleation efficiency of mineral dust aerosols, Environ. Res. Lett., 3, 025007, doi:10.1088/1748-9326/3/2/025007, 2008.

Murphy, D. M., Cziczo, D. J., Hudson, P. K., and Thomson, D. S.: Carbonaceous material in aerosol particles in the lower stratosphere and tropopause region, J. Geophys. Res., 112, D04203, doi:10.1029/2006JD007297, 2007.

Murray, B. J.: Inhibition of ice crystallisation in highly viscous aqueous organic acid droplets, Atmos. Chem. Phys., 8, 54235433, doi:10.5194/acp-8-5423-2008, 2008.

Peter, T., Marcolli, C., Spichtinger, P., Corti, T., Baker, B. M., and Koop, T.: When Dry Air Is Too Humid, Science, 314, 13991402, 2006.

Prospero, J. M. and Carlson, T. N.: Vertical and Areal Distribution of Saharan Dust over the Western Equatorial North Atlantic Ocean, J. Geophys. Res., 77, 5255-5265, doi:10.1029/JC077i027p05255, 1972.

Pruppacher, H. R. and Klett, J. D.: Microphysics of Clouds and Precipitation, Second Revised and Enlarged Edition with an Introduction to Cloud Chemistry and Cloud Electricity, vol. 38, edited by: Jacobson, M. Z., doi:10.1023/A:1005304329379, 1998.

Roeckner, E., Bäuml, G., Bonaventura, L., Brokopf, R., Esch, M., Giorgetta, M., Hagemann, S., Kirchner, I., Kornblueh, L., Manzini, E., Rhodin, A., Schlese, U., Schulzweida, U., and Tompkins, A.: The atmospheric general circulation model ECHAM5. Part I: Model description, Max Planck Institute for Meteorology Rep., 349, 127 pp., 2003.

Rogers, D. C., DeMott, P. J., Kreidenweis, S., and Chen, Y.: Measurements of ice nucleating aerosols during SUCCESS, Geophys. Res. Lett., 25, 1383-1386, 1998.

Salzmann, M., Ming, Y., Golaz, J.-C., Ginoux, P. A., Morrison, H., Gettelman, A., Krämer, M., and Donner, L. J.: Two-moment bulk stratiform cloud microphysics in the GFDL AM3 GCM: description, evaluation, and sensitivity tests, Atmos. Chem. Phys., 10, 8037-8064, doi:10.5194/acp-10-8037-2010, 2010.

Scott, N. A., Chédin, A., Armante, R., Francis, J., Stubenrauch, C., Chaboureau, J.-P., Chevallier, F., Claud, C., and Cheruy, F.: Characteristics of the TOVS Pathfinder Path-B Dataset, B. Am. Meteorol. Soc., 80, 2679-2701, doi:10.1175/15200477(1999)080<2679:COTTPP>2.0.CO;2, 1999.

Spichtinger, P. and Gierens, K. M.: Modelling of cirrus clouds - Part 2: Competition of different nucleation mechanisms, Atmos. Chem. Phys., 9, 2319-2334, doi:10.5194/acp-9-2319-2009, 2009.

Spichtinger, P. and Krämer, M.: Tropical tropopause ice clouds: a dynamic approach to the mystery of low crystal numbers, Atmos. Chem. Phys., 13, 9801-9818, doi:10.5194/acp-13-98012013, 2013. 
Stier, P., Feichter, J., Kinne, S., Kloster, S., Vignati, E., Wilson, J., Ganzeveld, L., Tegen, I., Werner, M., Balkanski, Y., Schulz, M., Boucher, O., Minikin, A., and Petzold, A.: The aerosol-climate model ECHAM5-HAM, Atmos. Chem. Phys., 5, 1125-1156, doi:10.5194/acp-5-1125-2005, 2005.

Sundqvist, H., Berge, E., and Kristjánsson, J. E.: Condensation and Cloud Parameterization Studies with a Mesoscale Numerical Weather Prediction Model, Mon. Weather Rev., 117, 1641-1657, doi:10.1175/1520-0493(1989)117<1641:CACPSW>2.0.CO;2, 1989.

Tegen, I., Harrison, S. P., Kohfeld, K., Prentice, I. C., Coe, M., and Heimann, M.: Impact of vegetation and preferential source areas on global dust aerosol: Results from a model study, J. Geophys. Res.-Atmos., 107, 4576, doi:10.1029/2001JD000963, 2002.

Vali, G.: Nucleation Terminology, J. Aerosol. Sci., 16, 575-576, 1985.

Wang, M. and Penner, J. E.: Cirrus clouds in a global climate model with a statistical cirrus cloud scheme, Atmos. Chem. Phys., 10, 5449-5474, doi:10.5194/acp-10-5449-2010, 2010.

Welti, A., Lüönd, F., Stetzer, O., and Lohmann, U.: Influence of particle size on the ice nucleating ability of mineral dusts, Atmos. Chem. Phys., 9, 6705-6715, doi:10.5194/acp-9-6705-2009, 2009.
Wiacek, A., Peter, T., and Lohmann, U.: The potential influence of Asian and African mineral dust on ice, mixed-phase and liquid water clouds, Atmos. Chem. Phys., 10, 8649-8667, doi:10.5194/acp-10-8649-2010, 2010.

Wielicki, B. A., Barkstrom, B. R., Harrison, E. F., Lee, R. B., Louis, S. G., and Cooper, J. E.: Clouds and the Earth's Radiant Energy System (CERES): An Earth Observing System Experiment, B. Am. Meteorol. Soc., 77, 853-868, doi:10.1175/15200477(1996)077<0853:CATERE>2.0.CO;2, 1996.

Wylie, D. P. and Menzel, W. P.: Eight Years of High Cloud Statistics Using HIRS, J. Clim., 12, 179-184, 1999.

Zhang, K., O’Donnell, D., Kazil, J., Stier, P., Kinne, S., Lohmann, U., Ferrachat, S., Croft, B., Quaas, J., Wan, H., Rast, S., and Feichter, J.: The global aerosol-climate model ECHAM-HAM, version 2: sensitivity to improvements in process representations, Atmos. Chem. Phys., 12, 8911-8949, doi:10.5194/acp-12-89112012, 2012.

Zuberi, B., Bertram, A. K., Cassa, C. A., Molina, L. T., and Molina, M. J.: Heterogeneous nucleation of ice in (NH4) $2 \mathrm{SO}_{4}-\mathrm{H}_{2} \mathrm{O}$ particles with mineral dust immersions, Geophys. Res. Lett., 29, 1504, doi:10.1029/2001GL014289, 2002. 